\section{Territorialidad, flujos espaciales y modalidades de tránsito yuxtapuestas en la red vial de los Valles Occidentales (siglos X-XX)}

( Pablo Méndez-Quirós Aranda

Departamento de Prehistoria, Universidad Autónoma de Barcelona, España.

\author{
Magdalena García Barriga \\ Instituto de Arqueología y Antropología, Universidad Católica del Norte / Centro de \\ Investigación del Hombre en el Desierto, Chile.
}

Recibido: 27 de abril de 2017. Aceptado: 28 de agosto de 2017 .

\title{
Resumen
}

La red vial andina constituye un legado cultural que sostuvo un uso continuo desde tiempos prehispánicos hasta la segunda mitad del siglo XX. Esta persistencia temporal convierte al sistema de caminos en archivos materiales e inmateriales de la historia regional, lo que fundamenta la importancia de su estudio desde una perspectiva arqueológica durante las últimas décadas. Investigaciones sobre las prácticas de movilidad en los Andes realizadas a la vera de los caminos del Desierto de Atacama, han revelado un panorama más complejo y dinámico que el inicialmente propuesto desde los modelos teóricos. Reconstruimos y analizamos la estructuración del sistema de caminos y senderos a partir de fotointerpretación de imágenes satelitales, complementada con información cartográfica y etnográfica. Luego evaluamos el rol de los caminos y las prácticas de movilidad para la construcción de la territorialidad indígena y su significación para la comprensión de las dinámicas sociales y las diferentes formas de habitarlo. Concluimos que la red vial se conformó a partir de la confluencia de modalidades de tránsito diversas y multidireccionales, delatando continuidades en el uso del espacio relacionadas con prácticas espaciales que hunden sus raíces en tiempos precoloniales.

Territoriality, space fluxes and juxtaposed transit modalities on the Western Valleys road network (X-XX centuries)

\author{
Abstract \\ The Andean trail network constitutes a cultural heritage that sustained a continuous use \\ from pre-Hispanic times until the second half of the twentieth century. This temporary
}

Palabras claves

Movilidad

Redes viales

Caminos troperos

Memoria

Andes Centro Sur

Palavras-chave

Mobilidade

Redes de trilhas

Caminhos tropeiros

Memória

Andes Centro-Sul
Key words

Mobility

Trail networks Ancient roads

Memory

South Central Andes 
persistence turns the road system into material and immaterial archives of the regional history, which underlies the importance of its study from an archaeological perspective during the last decades. Research on the mobility practices in the Andes, carried out at the side of the roads that cross the Atacama Desert, have revealed a more complex and dynamic panorama than what was initially proposed by the theoretical models. We reconstructed and analyzed the roads and trails structure system from satellite images photo interpretation, complemented with cartographic and ethnographic information. Later, the role of roads and mobility practices was evaluated for the construction of indigenous territoriality and its significance for the understanding of social dynamics and different ways of inhabiting. We conclude that the trail network was shaped by the confluence of different and multi-directional traffic modalities, revealing continuities in the use of space related to space practices that sink their roots in precolonial times.

\section{Introducción}

Por supuesto, no en todas partes es posible relevar el derrotero de las vías. (...) Es la fascinante miseria de la arqueología aplicada a la vialidad: la reconstrucción siempre problemática e incompleta de lo que ya no es. (...) Sin embargo, cuando las improntas de rutas están disponibles, aunque sea mediante el registro de unos pocos segmentos viales en el terreno, su análisis manifiesta con inmejorable claridad que la interacción interregional tiene un aspecto espacial concreto y que en los entresijos de la circulación por senderos y caminos existen actores, discursos, prácticas sociales y maniobras políticas que operan como una activa fuerza constitutiva de la composición y construcción de la propia interacción (Berenguer et al., 2011:247-248, destacado nuestro).

Los caminos constituyen rasgos lineales que intervienen y modifican el espacio con el propósito de comunicar lugares, dando forma a una red de asociaciones espaciales y socioculturales múltiples. Como se señala en el epígrafe, el diseño de esta red no es producto de una constitución azarosa o caótica, sino resultado de relaciones dialógicas entre el espacio, el territorio y las sociedades que lo habitan y transitan. Desde esta perspectiva, los caminos son expresiones concretas de la construcción, apropiación y producción del espacio y pueden hablarnos de la territorialidad en el pasado. Entendemos por "espacio" la manera singular como cada comunidad humana se apropia del espacio físico, lo construye, conceptualiza y comprende, convirtiéndolo en un producto social (Lefebvre, 1974). Consecuentemente, este espacio habitado tiene una historicidad inherente mediada por el lenguaje, que lo hace contingente, subjetivo y cambiante (Ingold, 1993; Thomas, 2001; Aliste y Núñez, 2015). El concepto de "territorio" agrega el componente político, en relación a las acciones y decisiones vinculadas con la tierra y el establecimiento de límites dentro de los cuales se produce la cohesión y reproducción social de una comunidad (Fábrega, 2004; González et al., 2014). De este modo, a diferencia del espacio, el territorio tiene límites, centros y periferias. El territorio siempre será un espacio reconocido y/o demandado por una comunidad, en el cual ésta establece una relación de propiedad sobre sus recursos naturales e hitos geográficos, los que pueden ser usados funcional y simbólicamente por ésta, o estar incorporados a ésta.

En los Andes, la red de caminos constituye un legado que es producto de un proceso histórico acumulativo de larga data, iniciado varios milenios antes de la conquista hispana, el cual tuvo como resultado una red intrincada y densa de ejes viales de distinta envergadura. Ante todo, éstos se definen mediante un diálogo con la desafiante topografía andina, compuesta de paisajes contrastantes donde los enclaves productivos y extractivos (agrícolas, pastoriles, costeros, mineros y mixtos) están rodeados por 
enormes extensiones de desierto y montañas (Núñez, 1976; Dollfus, 1981; Núñez y Nielsen, 2011). La efectividad de esta infraestructura se fundamenta en su vigencia hasta bien entrado el siglo XX, siendo usada por parte de las comunidades indígenas así como por la población foránea para llevar a cabo sus empresas económicas (Keller, 1946; Flores, 1975; Riviere, 1979; Lecoq, 1987; Inamura, 1988; Tomoeda, 1988; García y Romero, 2015; Choque y Muñoz, 2016; García y Ajata, 2016; Richard, et al., 2017). Más allá de estas últimas ocupaciones que se mezclan con los usos prehispánicos, el diseño enmarañado de la red así como su profundidad histórica constituyen ante todo un referente directo de la forma cómo las comunidades andinas habitaron y construyeron su espacio. En este contexto cultural, la movilidad constante que caracteriza a estas sociedades no debe comprenderse como una estrategia económica o medio para obtener algo, sino como una forma de vida, en que la movilidad se constituye como una práctica significativa donde se expresa una forma particular de comprensión del mundo que además produce espacialidad (Núñez, 1984; Tomasi, 2013).

En el norte de Chile, estos caminos denominados "troperos" por las comunidades indígenas locales, se mantuvieron plenamente vigentes hasta la década del sesenta del siglo XX, cuando se comenzaron a construir los caminos vehiculares y se aceleró el despoblamiento de los territorios indígenas por la migración hacia los puertos del Pacífico. En Arica, una mención escrita a mediados del siglo XX refleja la vigencia, relevancia y efectividad del sistema de caminos troperos como testigos de un gran dinamismo social y económico que existió en esta zona hasta el pasado reciente. "La tupida red de senderos permiten recorrer el departamento [de Arica] en cualquier sentido. La mula y el llamo continúan disfrutando de un monopolio casi completo en los transportes" (Keller, 1946:303). De esta forma, junto con la presencia de ramales que articulan a los pueblos actuales de origen colonial, la red vial tropera simultáneamente conecta con asentamientos prehispánicos que en algunos casos se emplazan próximos a dichos pueblos (Muñoz y Briones, 1996). De todos modos, la continuidad de su uso no implica que ésta se haya mantenido incólume ante las transformaciones históricas y territoriales ocurridas en épocas coloniales y republicanas, las que necesariamente debieron modificar los flujos, desactivando y activando rutas como consecuencia de las nuevas lógicas de ocupación del espacio principalmente ligadas a la explotación minera (González et al., 2014; Choque y Muñoz, 2016; Richard et al., 2017).

En términos arqueológicos, esta larga secuencia de ocupación implica la existencia de distintos componentes culturales y cronologías que se encuentran mezclados y yuxtapuestos sobre los caminos, generando una superposición y palimpsesto de distintas prácticas de movilidad implicadas en esta red. Esta condición cruza a nivel teórico y analítico los intentos por comprender las dimensiones materiales e inmateriales de los ejes viales, haciendo difícil, y acaso improductivo, la tarea de diseccionar capas temporales cerradas o asépticas.

Los antecedentes sobre la organización vial en los Valles Occidentales (Lumbreras, 1981) se centran en la región de Arica, haciendo referencia a las principales rutas que articularon la región desde épocas prehispánicas. Muñoz y Briones (1996) publicaron el primer estudio a escala regional, registrando cuatro rutas: las longitudinales Precordillerana y Costera, y las transversales que corren paralelo a los valles de Lluta y Azapa. Estos antecedentes se centran principalmente en la documentación de las arterias principales y el tráfico caravanero o de llameros especializados (Núñez, 1976; Núñez y Dillehay, 1995; Muñoz y Briones, 1996; Briones et al., 2005). Al contrario, en la última década se ha venido demostrando que el caravaneo corresponde solamente a una de las dimensiones o modalidades de tránsito dentro de un abanico de posibilidades, incluyendo tránsitos ligados a sistemas de trueque menos especializados, de menor escala o distancia, a circuitos de pastoreo, a la mantención de chacras en lugares distantes, actividades de caza y recolección así como aprovisionamiento de 
recursos variados, contextos festivos, ceremoniales, sociales o por parentesco, entre otros (Valenzuela et al., 2011; Pimentel et al., 2011; García y Romero, 2015; García y Ajata, 2016). Estas prácticas son impensables sin una red vial lo suficientemente extensa, robusta e interconectada, que sea capaz de mediatizar movimientos de personas, grupos familiares y colectivos mayores entre localidades situadas a corta, mediana y larga distancia (Muñoz y Briones, 1996; Mendez-Quiros, 2016).

En el presente trabajo elaboramos una reconstrucción exhaustiva de la red vial en la región de Valles Occidentales, buscando identificar la diversidad de modalidades de tránsito que la componen para avanzar hacia la comprensión de la espacialidad indígena. El área de estudio cubre un área de $150 \mathrm{~km}$ de largo por $100 \mathrm{~km}$ de ancho en el extremo norte de Chile, específicamente entre los valles de Lluta $\left(18,4^{\circ} \mathrm{S}\right)$ por el norte y de Aroma $\left(19,8^{\circ} \mathrm{S}\right)$ por el sur, abarcando desde el nivel del mar hasta el piso precordillerano (0-4.000 msnm). Evidentemente, las arterias principales registradas al interior de este espacio sobrepasan sus límites, evidenciando que los caminos registrados constituyen solo una porción de la extensa red vial que desde tiempos prehispánicos permitió la integración cultural, social y económica del área Centro Sur Andina (Núñez, 1976; Núñez y Dillehay, 1995).

\section{Perspectivas y modelos para la movilidad en los Andes Centro Sur}

La arqueología tradicionalmente ha centrado su interés y esfuerzo en el estudio de asentamientos contenidos en sí mismos, tales como poblados, cementerios, basurales, espacios rituales, sitios rupestres, entre otros. Es allí donde comúnmente se buscan las evidencias materiales que nutren con datos empíricos a interpretaciones y relatos sobre el espacio-tiempo del pasado. Sin embargo, si alejamos el foco para centrarnos en los caminos o elementos viales comunicantes, encontramos una valiosa fuente de información que impulsa a preguntarnos sobre temáticas socioculturales de alcance regional que rebasan los límites y las fuentes de la arqueología clásica, al apuntar a formas de ocupación del territorio y relaciones espaciales establecidas entre asentamientos.

Caminos y senderos se definen como trayectorias espaciales generadas como consecuencia del tránsito de personas y grupos sociales, organizadas en forma de redes y compuestas por una infinidad de tramos con envergaduras e historias variables y heterogéneas. Cuentan con una dimensión material, relacionada con aspectos tangibles de los caminos y la impronta de su uso; y una dimensión inmaterial que refiere a relaciones y prácticas sociales generadas en torno a dicho tránsito. La conjunción de ambas dimensiones puede ser estudiada desde una perspectiva arqueológica, orientada hacia la comprensión del proceso de conformación de esta red y las diversas modalidades de tránsito implicadas, favoreciendo la integración de comunidades a un territorio y sus recursos.

Las redes viales en cuanto son una manifestación directa de la movilidad, nos permiten visualizar la red efectiva de conexiones intra e interregionales, brindando una imagen de integridad, continuidad y unidad de un amplio territorio sobre las relacionales entre grupos humanos espacialmente distanciados pero socialmente vinculados notablemente entre sí (Torres-Rouff et al., 2012:168).

Desde la perspectiva anterior, los caminos pueden ser considerados como expresiones concretas del proceso de construcción, apropiación y producción del espacio. En este contexto, es inevitable referirnos al intenso tráfico de objetos e ideas que articularon esta vasta región mediante una movilidad pedestre, apoyada en algunos casos por animales de carga (Núñez, 1976; Núñez y Dillehay, 1995; Muñoz y Briones, 1996; Pimentel et al., 2011). La movilidad andina, más que una estrategia económica, es parte de una forma 
de vida (sensu Núñez, 1984) que ha sido fundamental en el habitar de este espacio desde su poblamiento inicial hace unos 12.800 años (Santoro et al., 2011; Latorre et al., 2013). Esta articulación fue muy efectiva, permitiendo la integración cultural y territorial en los Andes Centro Sur desde épocas precoloniales.

Uno de los primeros modelos teóricos que intentó explicar la movilidad en los Andes como una práctica sistemática y culturalmente determinada se desprende del trabajo de Murra (1972), quien a partir de una atenta lectura a documentos coloniales tempranos (siglo XVI) propuso que grupos aymaras del Titicaca sostuvieron una ocupación espacialmente discontinua de pisos ecológicamente diferenciados. Estos grupos habrían alcanzado el ideal andino de complementariedad de recursos siguiendo distintas estrategias, incluyendo la colonización y el trueque (Salomon, 1985; Van Buren, 1996; Gallardo, 2013) particularmente al tratarse de productos redundantes (charqui de carne/pescado seco, lana/algodón). Estos postulados calaron hondo en los estudios andinos, iniciando una fecunda línea de investigación que tuvo un impacto significativo en las interpretaciones sobre el pasado prehispánico y colonial.

Pocos años más tarde, Núñez y Dillehay (1995) plantearon la "Movilidad Giratoria" como un modelo que buscaba ajustarse a la realidad de regiones señaladas como periféricas en el modelo anterior norte de Chile, sur de Bolivia y noroeste de Argentina. Se plantea que la complementariedad de recursos fue articulada por un sistema de caravanas realizando movimientos en espiral entre "asentamientos-ejes" para poner en circulación la producción de pisos ecológicos diferenciados y complementarios. Para estos autores, este sistema dependería de la disposición de grupos o tropas numerosas de llamas cargueras para sostener el tráfico, por lo que su control debía estar en manos de grupos altiplánicos capaces de organizar la circulación de bienes a lo largo de la transecta costa -altiplano- selva. De esta forma, sitúan en el centro del debate a los asentamientos-ejes, que definen su movimiento por un vasto territorio elongado, abasteciendo a las caravanas y redistribuyendo sus productos a nivel local, regional e interregional (Núñez y Dillehay, 1995:27; Berenguer, 2002).

La Movilidad Giratoria considera al sistema caravanero como el sostén de la complementaridad de recursos y asume que la integración territorial depende del caravaneo. Desde esta perspectiva no hay espacio a soluciones desarrolladas por grupos agricultores, quienes sostuvieron una producción centrada en los valles aprovechando espacios y quebradas para aumentar y diversificar la producción de manera independiente a la movilidad caravanera (Durston y Hidalgo, 1997; Santoro et al., 2010). Por ende, es difícil seguir sosteniendo la existencia de relaciones de dependencia de grupos agricultores a manos de pastores para la movilización de su producción. En suma, la Movilidad Giratoria al centrarse en las caravanas asigna un rol trascendental a los pastores altiplánicos y el tráfico a larga distancia, sin dejar espacio a otras formas de circulación de objetos documentados por la etnografía y la arqueología.

Distintos estudios han comenzado a visibilizar sistemas de movilidad que funcionaron en paralelo, asociándose a una serie de prácticas de movilidad como la multi residencia o las múltiples formas de adquisición directa de recursos que no implican una colonización (García y Romero, 2015; García y Ajata, 2016) siendo estos elementos clave para comprender la integración territorial en el Centro Sur Andino. En este sentido, Valenzuela y colaboradores (2011) dan cuenta de un tráfico regional y local no caravanero en el valle de Lluta, donde se identifican sitios con arte rupestre que forman parte de dinámicas de movilidad sostenidas por las propias comunidades agricultoras. Más al sur, en la región central del Desierto de Atacama se han documentado otras modalidades de tránsito características de grupos costeros sin contar con animales de carga (Ballester y Gallardo, 2011; Pimentel et al., 2011; Torres-Rouff et al., 2012). 
En síntesis, existe cada vez más consenso sobre la existencia de prácticas de interacción diversas que combinan circuitos de movilidad de distintos alcances (corta, media y larga distancia) y trayectoria (verticales, horizontales y diagonales). Por tanto, como resultado de estas estrategias múltiples, la red se conforma por una yuxtaposición de vías de circulación acorde a la convergencia de un amplio espectro de prácticas de movilidad.

\section{Metodología}

Siguiendo los planteamientos de Trombold (1991) y Berenguer y colaboradores (2005), emprendimos un acercamiento macromorfológico u holístico de los caminos, buscando comprender la organización del sistema vial atendiendo a su extensión, conectividad y su relación con un paisaje culturalmente construido (Castro et al., 2004). A partir de un trabajo de fotointerpretación, registramos las trayectorias de caminos y senderos, junto con relevar la fisonomía e interrelaciones de la red vial.

Las vías pueden ser resultado de procesos diversos que incluyen desde una formación espontánea por el uso reiterativo de ciertas trayectorias entre dos o más lugares, hasta aquellas que son resultado de esfuerzos mancomunados y planificados para diseñar, construir y consolidar caminos formales que facilitan la interacción y transmisión de conocimientos, así como el acceso, utilización y circulación de recursos. Recientemente, Pimentel (2012:84-86) ha definido como red vial al entramado de vías que se disponen en un territorio, las que pueden tener un alcance local, intrarregional e interregional. Las vías de circulación son aquellos trayectos tangibles que pueden ser observados en el espacio, incluyendo senderos caracterizados como sendas producidas por el tránsito redundante, y caminos o vías formalizadas construidas de forma planificada con un propósito específico. De acuerdo al autor, sólo estas últimas podrían contar con inversión de trabajo, elementos de ingeniería (terraplenes, puentes, etc.) y prácticas de mantenimiento. En un nivel de generalidad mayor define las rutas, consistentes en trayectos virtuales que comunican lugares.

Si bien estas definiciones son adecuadas para conceptualizar las vías, no agotan la variabilidad empírica observada. La larga historia de uso de muchos de estos segmentos es contraria a la propuesta de que ciertos caminos responden a propósitos específicos, constituyendo un sesgo que no reconoce los usos múltiples y yuxtapuestos que estos adquieren desde una perspectiva de larga duración. En esta línea, una categorización detallada de las vías capaz de reconocer la variación entre segmentos requiere de un registro micromorfológico para relevar sus atributos y variaciones, acercamiento que se contrapone al propuesto en este trabajo que aspira a comprender la estructuración de la red vial a una escala regional.

Considerando las limitaciones de un registro a partir de fotointerpretación de imágenes satelitales, empleamos las categorías caminos troncales y senderos. Los caminos troncales (Figura 1) son vías que alcanzaron un uso masivo, reiterado o continuo en el tiempo y gran conectividad espacial, lo que se expresa en trayectorias extensas que articulan múltiples nodos. Frecuentemente, esto coincide una trocha amplia donde pueden reconocerse surcos paralelos múltiples con mayor contraste respecto al sustrato por el cual transitan. Por su parte, bajo la categoría sendero (Figura 2) se engloban vías de distinta envergadura, incluyendo desde sendas simples a caminos que en algunos segmentos pueden asemejarse a los troncales, salvo por su continuidad y conectividad. En este sentido, los atributos de los elementos viales no son constantes ya que varían en función a la pendiente, el tipo de sustrato y la cubierta vegetal. Esto significa que algunos caminos troncales pueden incluir segmentos con atributos sencillos y efímeros, del mismo modo que un sendero puede dar paso a senda con alta inversión de trabajo 


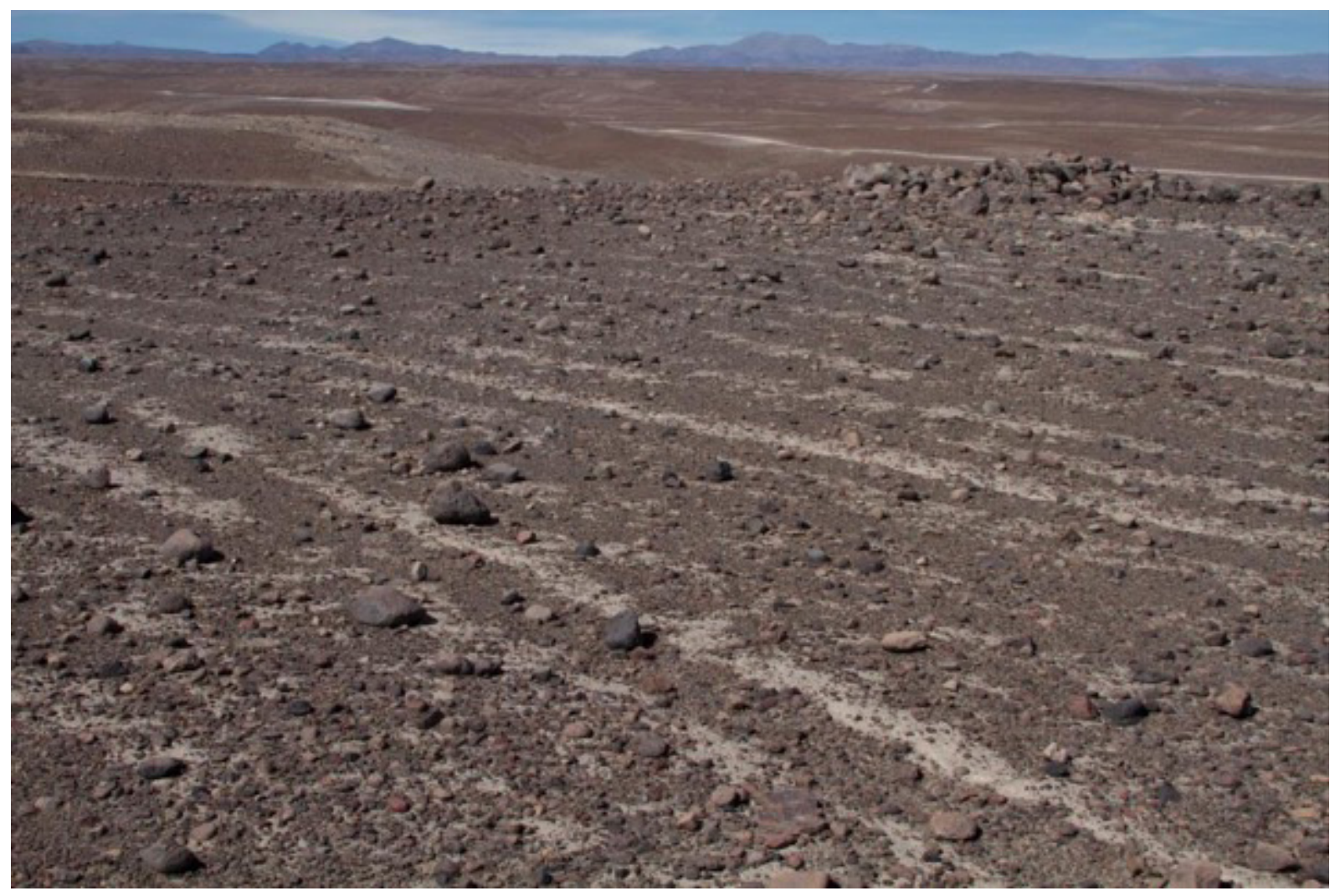

al llegar a un poblado. Por tanto, al jerarquizar los caminos aplicamos un criterio cualitativo ponderando cada vía y considerando las variaciones entre los distintos segmentos que la componen.

$\mathrm{Al}$ interior de la red vial se define un conjunto de nodos de interacción que cumplieron un rol central en la articulación territorial de los Valles Occidentales meridionales. Estos corresponden generalmente a lugares con disposición de agua permanente, definidos en dos niveles jerárquicos de primer y segundo orden en función al grado de conectividad que sostuvieron al interior de la red. Los primeros se sitúan en espacios con buen potencial productivo, generalmente agrícola o agro ganadero y cuentan con al menos cinco conexiones troncales. Los segundos muestran una conectividad menor, con hasta cuatro conexiones troncales, y se sitúan en lugares con potencial agrícola o ganadero limitado, funcionando algunos como estaciones logísticas que favorecen la articulación del sistema vial.

La reconstrucción de la red vial se nutre de tres fuentes de información complementaria. La primera consiste en el seguimiento y registro de las trayectorias concretas de las vías de circulación, mediante la fotointerpretación de imágenes satelitales disponibles a través del geoportal Google Earth. Las vías fueron representadas con poli líneas vectoriales para graficar los segmentos identificados, empleándose una resolución fina capaz de dar cuenta de las distintas soluciones tomadas por los caminantes para sortear los accidentes del paisaje, incluyendo caminos, senderos, variantes y vías alternativas.

La identificación y seguimiento de vías se realizó mediante un barrido sistemático del área de estudio a una escala adecuada para reconocer la impronta de caminos y senderos a partir de $1 \mathrm{~m}$ de ancho. Para organizar el proceso de fotointerpretación se subdividió el área de estudio en cuadrantes, los que fueron sometidos a una completa revisión en varias etapas, empleando imágenes satelitales de distintos años para contrarrestar problemas en la calidad y nitidez (brillo, contraste y luminosidad). Todas las vías fueron seguidas varias veces para reducir los márgenes de error y omisiones.
Figura 1. Camino tropero en el piso de piedemonte, donde se notan los característicos surcos múltiples en asociación a una apacheta (arriba a la derecha). Fuente: Fotografía de Pablo Mendez-Quiros. 


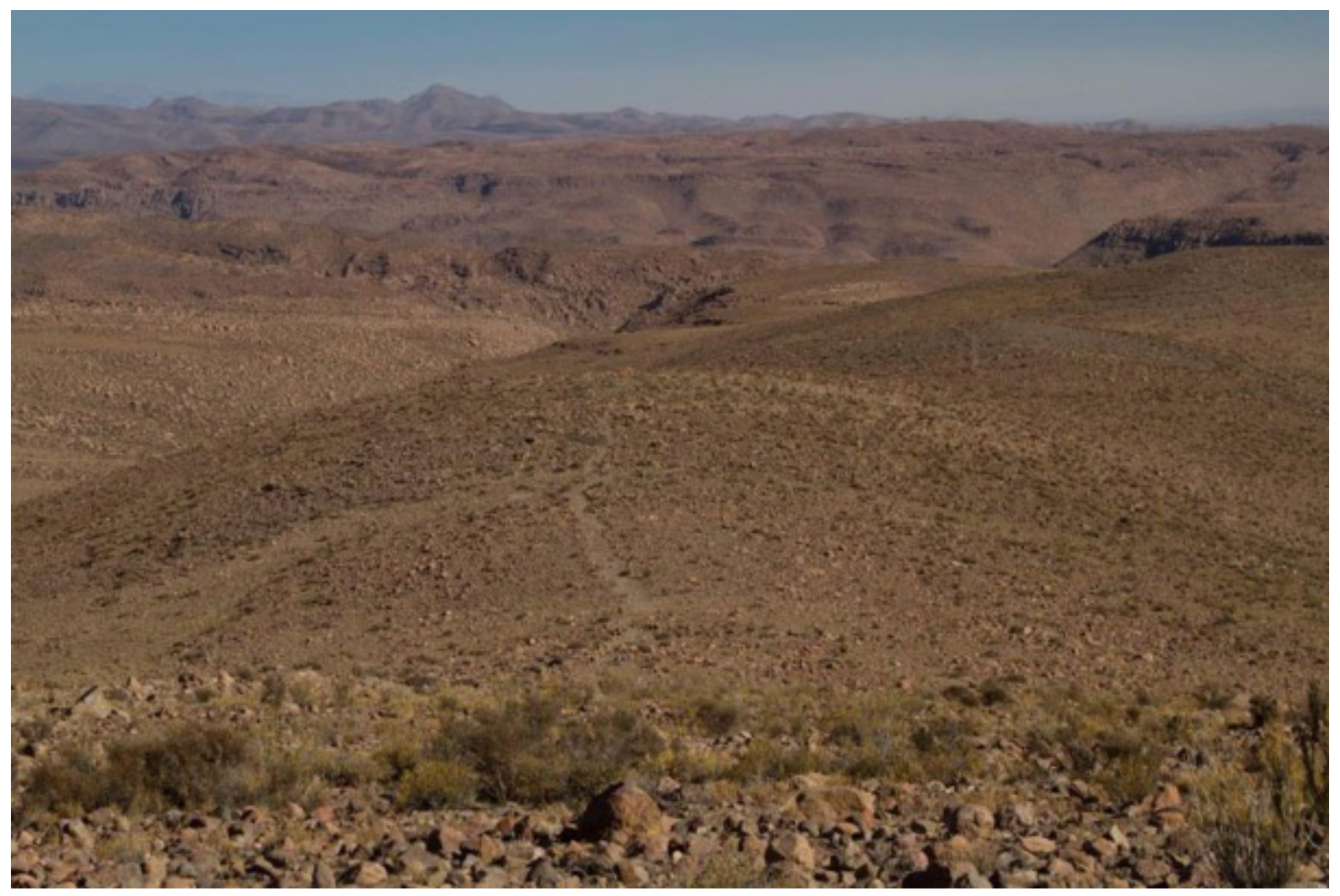

Esta información fue procesada usando el software ArcMap 10.3., donde se integró el levantamiento de las vías de circulación con un modelo digital de elevación que representa las variaciones topográficas, contrarrestando así el aplanamiento que genera una representación bidimensional. Se incorporaron referencias a las principales geo formas del paisaje y su toponimia, así como a los pueblos y localidades para lograr una de adecuada contextualización espacial de la red vial. De esta forma, generamos un completo registro de las vías que conforman la red (Figura 3), para luego jerarquizar aquellas que por su envergadura y conectividad pudieron estructurar las prácticas de movilidad y el funcionamiento del sistema vial (Mendez-Quiros, 2016).

Previo al trabajo de fotointerpretación, se realizó un trabajo de reconocimiento en terreno sobre caminos en distintas regiones del área de estudio, así como en Tarapacá y Atacama. A partir de estas experiencias, emprendimos el seguimiento remoto de las vías de comunicación entendiendo sus atributos empíricos y los factores que inciden en su preservación, lo que permitió evaluar la eficacia y limitaciones de la fotointerpretación (Saintenoy et al., 2017). La condición de aridez en el área de estudio por la casi nula incidencia de lluvias junto con la inexistencia de una cubierta vegetacional bajo los $2.500 \mathrm{~m}$, favorecen una adecuada visibilidad de las vías de circulación. Sobre los $2.500 \mathrm{~m}$ se comienza a desarrollar una cubierta vegetacional que aumenta en altura correspondiente a pasturas, matorrales y cactáceas de baja densidad que reducen la visibilidad de los senderos menos consistentes.

Una segunda fuente de información proviene de la revisión de cartografías históricas elaboradas entre los siglos XVIII al XX. Generalmente, hasta el siglo XIX estas cartas carecen de información referente a caminos, aunque aportan datos sobre el relieve y toponimia asociada a los principales centros poblados. La representación más temprana de caminos en el área, corresponde a un mapa de 1791 donde se ilustra en términos generales la conexión de Potosí con la costa pacífica, a través de Arica y Cobija (Cañete y Domínguez, 1952 [1791]). Por lejos la carta más completa y detallada pertenece al
Figura 2. Sendero surcando el espacio andino en el piso de puna baja. Nótese las condiciones de visibilidad a mediana distancia. Fuente: Fotografía de Pablo Mendez-Quiros. 


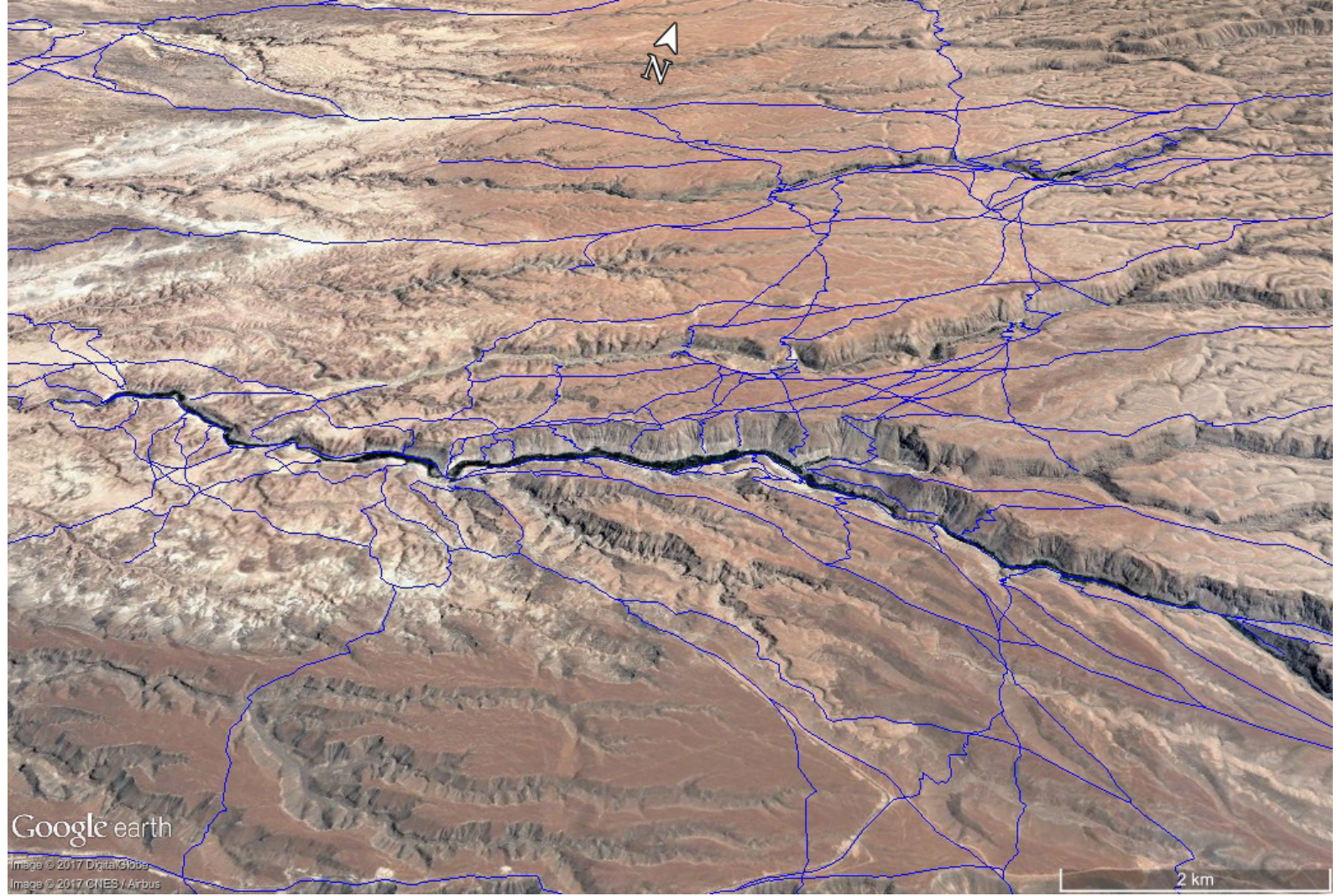

"Mapa de Chile" elaborado en 1910 por Nicanor Boloña y el ingeniero Luis Risopatrón. Contiene un levantamiento completo y minucioso de caminos formales, senderos para tránsito pedestre y un fino registro de toponimia, abarcando las provincias de Tacna, Arica y Tarapacá. Asimismo, en el levantamiento de Keller (1946) se registra el sistema de caminos troperos y vehiculares con buena resolución, aportando un buen estudio aplicado a la región de Arica. Esta data sirvió para corroborar algunas vías con segmentos borrados por la superposición de caminos actuales o por erosión, así como contrastar la toponimia de los nodos y, en general, guiar y afinar los resultados alcanzados por la fotointerpretación.

Por último, una tercera fuente proviene de una aproximación etnográfica centrada en la memoria de pobladores de los valles de Codpa, Esquiña y Nama, así como de sus vecinos los pastores de Mulluri. Este trabajo comenzó a realizarse el año 2011 y está actualmente en curso. Hemos realizado entrevistas, talleres y observación participante, recorriendo y documentando algunos caminos troperos acompañando a arrieros locales, portadores de un profundo conocimiento del espacio y de la red vial (García 2015, 2018; García y Ajata, 2016). Desde un enfoque etnoarqueológico (Hernando, 1995; Aldunate et al., 2003), este trabajo ha permitido contrastar, orientar y nutrir las inferencias que hacemos desde la arqueología y la fotointerpretación, especialmente en relación a aspectos inmateriales implícitos en las distintas modalidades de tránsito, así como las relaciones sociales y tecnologías que operan en torno al éstas.

\section{Estructuración de la red vial: caminos, nodos y senderos}

La red vial de la región de Valles Occidentales se compone de cientos de ejes viales de distinta envergadura y grados de formalización, conformando un sistema enmarañado
Figura 3: Modelo digital de caminos y senderos no jerarquizados en uno de los cuadrantes estudiados. Fuente: Elaboración propia. 
de caminos que intercomunican pueblos, enclaves productivos y otros lugares. Las vías cubren toda el área de estudio con densidades de senderos muy variables, sin que existan sectores carentes de vías de comunicación debido a la alta ubicuidad de estas evidencias. En este sentido, en general la ausencia de registros se explica por la alteración de la superficie o las características topográficas específicas que son inadecuadas para el tránsito regular. A partir de los criterios previamente expuestos, se propone una estructuración de la red vial a partir de caminos troncales, senderos y nodos que se ilustran en la Figura 4.

\section{Caminos troncales}

Los caminos troncales operan como derroteros centralizadores del tránsito de personas y el tráfico de productos, por lo que cumplen un rol gravitante en la organización de la red vial. Se identificaron un total de diez, tres de los cuales presentan un trazado longitudinal (norte-sur) y siete un trazado transversal (este-oeste). Adicionalmente, se identificaron una serie de diagonales que corresponden a caminos del mismo nivel jerárquico que establecen enlaces entre longitudinales y transversales, consolidando una macro estructura vial densamente interconectada.

\section{Longitudinales}

Los caminos troncales longitudinales suelen transitar por uno o dos pisos ecológicos en paralelo a los principales cordones montañosos que atraviesan la región: Cordillera de la Costa (ca. $1.100 \mathrm{msnm}$ ), Sierra de Huaylillas (ca. $3.500 \mathrm{msnm}$ ) y la Cordillera Central (ca. $4.800 \mathrm{msnm})$.

La trayectoria del Camino Costero es paralela al borde oriental de la Cordillera de la Costa, atravesando las pampas intermedias que, con intermitencias, comunica las regiones de Tacna (Perú), Arica y Tarapacá (Chile). Específicamente, se desplaza a través de los valles bajos de Caplina, Lluta, Azapa y Chaca, flanqueando una de las áreas agrícolas más productivas de la región. $\mathrm{Al}$ sur de Chaca se bifurca en dos variantes que comunican con la quebrada de Tarapacá. La primera enfrenta condiciones ambientales más áridas al ingresar a la Pampa del Tamarugal valiéndose de una serie de oasis para el cruce a través del desierto entre los 800 y 1.300 m, espacio que concentra recursos escasos pero fundamentales para la circulación. La segunda variante circula a través del piedemonte, alcanzando una altura máxima de $1.900 \mathrm{~m}$, accediendo a algunos enclaves importantes en el curso inferior y medio de las quebradas.

El Camino Huaylillas comunica el curso bajo de Caplina con los cursos intermedios de los valles de Lluta y Azapa, y hacia el sur alcanza hasta los $2.600 \mathrm{~m}$ de elevación, generando un importante enlace vial asociado a la ecozona de chaupiyunga. Este piso ofrece condiciones micro climáticas muy apetecidas para una producción agrícola especializada y de gran productividad, pese a la reducida extensión de la superficie cultivable, vinculándose a la producción de coca en el pasado (Santoro et al., 2009). Este camino tiene gran potencial informativo para la comprensión de las dinámicas sociales desplegadas en la cuenca intermedia de los valles de Lluta y Azapa; y la cuenca media de Codpa y Camarones.

Por su parte, el Camino Precordillerano es un eje vertebral que comunica el sistema de poblados ubicados en la puna baja (2.800-3.300 msnm) entre las regiones de Arica y Tarapacá, pasando por Putre, Belén, Cobija, Esquiña, Camiña y Chiapa, entre otros nodos intermedios. Este espacio se caracteriza por su potencial productivo agro ganadero, subsidiario del régimen de lluvias de verano que entrega buenas condiciones para el desarrollo de una agricultura de altura y el pastoreo de ganado. Si bien la relevancia de este camino había sido señalada previamente (Santoro, 1983; Muñoz y Briones, 1996), no existía claridad sobre su trayectoria al sur de Camarones. 


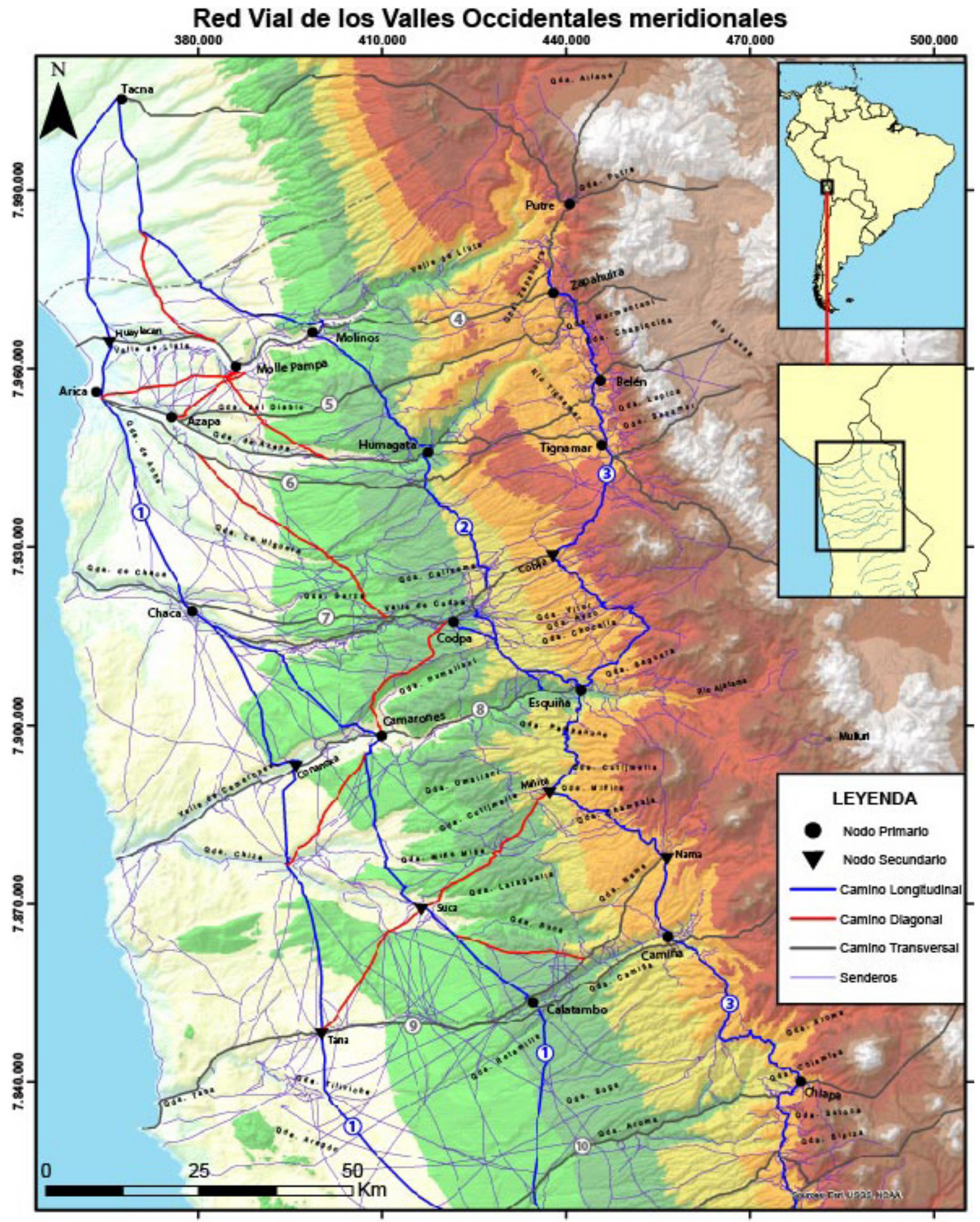

A lo largo de estos tres ejes se estableció una conectividad horizontal, inter piso, comunicando asentamientos y activando vínculos de complementariedad horizontal (sensu Rostworowski, 1977) que responden a las notables diferencias productivas entre uno y otro valle por su condición hídrica y espectro de especies cultivadas (Álvarez, 1991). Estas relaciones horizontales tienen una profundidad temporal notable, reconociéndose vinculaciones y prácticas de interacción entre los valles de Arica durante al menos los últimos ocho siglos.
Figura 4. Red Vial tropera de la región de Valles Occidentales. Caminos troncales, nodos y caminos no troncales o senderos. Caminos troncales: 1.- Costero, 2.- Huaylillas, 3.- Precordillerano 4.- Lluta, 5. Azapa Norte, 6.- Azapa, 7.- Chaca, 8.- Camarones, 9.- Camiña. 10.Aroma. Fuente: elaboración propia. 


\section{Transversales}

Son siete los caminos transversales que se entrelazan con los anteriores, cuya circulación responde al tránsito a través o en paralelo a los valles siguiendo una orientación general este - oeste, que permite conectar verticalmente la costa y puna, articulando los distintos espacios ecológicos de la gradiente altitudinal andina. En su curso inferior estos valles tienen terrazas fluviales más amplias y a medida que aumenta la altitud se vuelven más profundas, estrechas y escarpadas, limitando las alternativas para la circulación.

Entre las cuencas de Lluta y Azapa se reconocen tres caminos transversales: Lluta, Azapa Norte y Azapa, los que conectan la costa de Arica con el altiplano de Parinacota, las cuencas altoandinas del río Lauca y del Salar de Surire. La concentración de troncales y senderos en el área se puede correlacionar con el excepcional potencial agrícola que caracteriza a ambas cuencas en relación al resto de la región, tanto los valles bajos con sus cabeceras (Putre, Belén y Tignamar), donde se han relevado una alta densidad de asentamientos de diferentes épocas (Niemeyer, 1972; Santoro y Chacama, 1982; Saintenoy et al., 2017).

Otros caminos troncales transversales que permiten la movilidad vertical se asocian a los valles de Chaca, Camarones y Tana, los cuales poseen una capacidad productiva menor que los anteriores, aunque no por ello menos importante. Esto se explica en parte por la existencia de una clara gradiente decreciente de caudales hacia el sur a consecuencia de la disminución del régimen de lluvias estivales, lo que impacta en la distribución y cobertura de la flora y tamaño de los bofedales altoandinos.

Por último, el Camino Aroma flanquea el área de estudio por el sur. Allí se manifiestan las claras diferencias geográficas que existen entre los Valles Occidentales y la región de Tarapacá, al desaparecer los valles exorreicos y dar paso a una extensa llanura híper árida donde desembocan una serie de cursos endorreicos que drenan la banda occidental de la Cordillera de los Andes. La ocupación humana en esta área es menos intensa y se concentra en las tierras altas y oasis dispersos a lo largo de las quebradas.

Las arterias descritas complementan el estudio previo de Muñoz y Briones (1996), a partir del registro de un camino longitudinal intermedio y tres caminos transversales no descrito previamente. Asimismo, hemos registrado nueve diagonales que hacen más fluida la conectividad troncal al interior de la red, conectando directamente distintas troncales longitudinales y transversales. La mayor densidad de estos enlaces fue registrado entre las cuencas de Lluta y Azapa, espacio que destaca por ser indiscutiblemente uno de los más interconectados de la región. Más al sur, entre los valles de Camarones y Tana, los enlaces aumentan la conectividad troncal entre ambas cuencas, especialmente en los cursos medio y superior.

\section{Nodos}

A lo largo de los caminos troncales una serie de lugares se consolidaron como nodos que articularon la movilidad dentro de la red. Pueden ser resultado de la actividad productiva de núcleos poblados situados en sectores particularmente fecundos, entendidos en el sentido asignado por Núñez y Dillehay (1995) a los asentamientos-eje como activadores de circuitos de complementariedad. Pero también pudieron corresponder a enclaves estratégicos, asociados a pequeños contingentes poblacionales y lugares con potencial productivo marginal, pero situados en puntos de convergencia de caminos troncales, funcionando como estaciones importantes (cfr. Nielsen, 1997).

La distribución espacial de los nodos sigue un comportamiento diferencial coherente con el panorama reseñado para los caminos troncales, siendo un buen indicador para entender los espacios que alcanzaron mayor integración a la red vial asociada a una 
movilidad más intensa. Así, los valles de Azapa y Lluta cumplen un rol sobresaliente en la articulación de la red vial albergando la mayor cantidad de nodos. El valle de Lluta cuenta con cuatro nodos de primer orden y uno de segundo orden, distribuidos a lo largo de la cuenca en los sectores costero (Huaylacán), fértil (Molle Pampa), intermedio o chaupiyunga (Molinos), y dos en el curso medio y superior (Zapahuira y Putre). El valle de Azapa cuenta con cinco nodos de primer orden, ubicados en la costa (Arica), el curso inferior (Azapa), el curso intermedio (Humagata) y dos en el curso superior (Belén y Tignamar).

El valle de Chaca cuenta con dos nodos de primer orden en su curso bajo y medio (Chaca y Codpa), y uno de segundo orden en el curso superior que coadyuva en la articulación vial con el Camino Precordillerano (Cobija). Considerando la cantidad de enlaces con caminos troncales, el nodo Codpa destaca como uno de los puntos más interconectados en la red vial, luego de los nodos en Lluta y Azapa.

La cuenca de Camarones es la que cuenta con mayor número de nodos, lo que se explica por ser la más extensa de la región, donde reconocemos un comportamiento claramente diferenciado entre las subcuencas Camarones y Chiza. Camarones presenta dos nodos de primer orden en el curso medio (Camarones) y superior (Esquiña) y uno de segundo orden en el curso inferior (Conanoxa). La sub cuenca Chiza, por su parte, se articula con tres nodos de segundo orden, uno ubicado en el curso medio (Suca) y dos en el curso superior (Miñita y Nama), estableciendo una conectividad levemente mayor con el valle de Camiña.

El valle de Camiña se articula a través de dos nodos de primer orden en el curso medio (Calatambo y Camiña), los que funcionan como umbrales que circunscriben el segmento más fértil del valle, articulándose hacia el norte y el sur por senderos que surcan la Pampa del Tamarugal y las cabeceras de las quebradas; y uno de segundo orden en el curso inferior (Tana). Presenta una conectividad levemente más fluida hacia el norte, y en este contexto el nodo Nama opera como enlace intermedio en el tránsito hacia la cuenca media de Camarones. Esta situación se explica por la ausencia de nodos en la pampa del Tamarugal dada su condición desértica, lo que también incide en la centralización de la circulación por la pampa a través de dos rutas, por el borde occidental y a través del piedemonte.

Finalmente, la quebrada de Aroma, mantiene un canal de comunicación importante hacia el norte que comunica con Nama, pero se identifica una mayor proliferación de senderos y caminos hacia el sur, a consecuencia de la gran conectividad que alcanza el nodo Tarapacá (Zori et al., 2017).

\section{Senderos}

Bajo la categoría sendero se agrupa una amplia diversidad de ejes viales de menor magnitud que los caminos troncales, concentrados especialmente en los cuadrantes ubicados en el curso inferior de los valles de Lluta y Azapa, cabecera de Azapa y curso medio y superior de Codpa y Camarones, donde se observa una retícula densa en la que se yuxtaponen múltiples trayectorias. Su impronta más tenue y morfología estrecha podría ser indicativo de un tránsito pedestre cuyas trayectorias son informativas de las formas de circulación, condiciones topográficas y productivas, donde las tropas de animales no fueron tan importantes. En este sentido, pueden ser entendidos como soluciones adoptadas por las poblaciones locales para dar respuesta a requerimientos de tipo económico, social y ceremonial (Mendez-Quiros, 2016). Por tanto, nos enfocamos en tres cuadrantes que presentan diferentes configuraciones viales, a través de las cuales esperamos acercarnos a las lógicas de utilización del espacio que inciden en su conformación. 


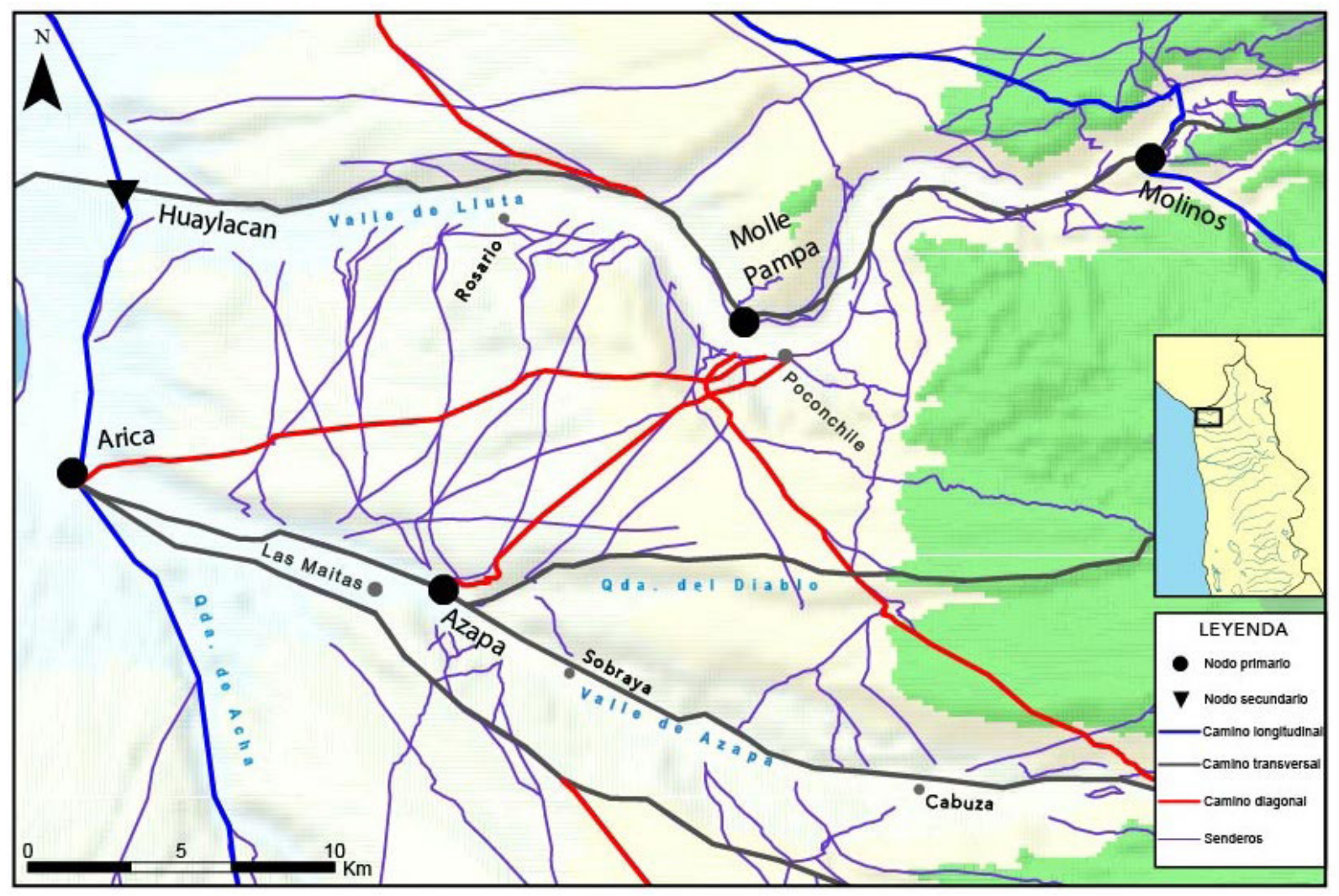

En primer lugar, en el cuadrante del curso inferior de los valles de Lluta y Azapa (Figura 5), se establece una fluida comunicación inter valle con un predominio de senderos longitudinales. Esta conectividad interfluvial no requiere de soluciones logísticas com-

Figura 5. Red vial en el curso inferior de los valles de Lluta y Azapa. Fuente: elaboración propia. plejas, ya que se puede realizar el cruce entre ambos valles sin mayores dificultades en media jornada de caminata. Es altamente probable que, por contar ambos valles con una producción diferenciada como consecuencia de las diferentes calidades y recargas hídricas (Alvarez, 1991), se haya sostenido un flujo productivo entre ambos, circulando personas (trabajo), insumos (semillas), herramientas (indumentaria agrícola) y, evidentemente, una fracción de la producción como parte de relaciones de complementariedad.

Para el traslado de productos agrícolas entre valles es fundamental contar con animales de carga, pudiendo tener circuitos más normados que los usados por caminantes. En suma, las conexiones interfluviales entre Lluta y Azapa pudieron sostener una movilidad asociada a animales que debió contar con una organización mayor usando circuitos que podrían confluir hacia caminos troncales, al mismo tiempo que se pudo desarrollar una activa movilidad pedestre gracias a la cual se alcanzó una intensa conectividad en curso bajo de ambas cuencas. Es plausible sugerir que, durante ciertos momentos del ciclo productivo agrícola cuando se requiere abundante mano de obra, pudieran existir estrechos lazos entre ambos valles, siendo común los traslados entre ambos para el desempeño de labores agrícolas.

Por otra parte, en el cuadrante de la cabecera de Azapa también se reconoce alta densidad de senderos que generan un entramado multidireccional. La topografía del área propicia una movilidad longitudinal a través del corredor natural formado entre la sierra de Huaylillas y la Cordillera Central a través de senderos que corren paralelos al Camino Precordillerano, siguiendo la cota de los asentamientos humanos (3.000-3.500 m). En un sentido transversal, varios senderos confluyen en los caminos troncales Lluta, Azapa Norte, Azapa y Chaca. Gran parte de estos senderos conectan 


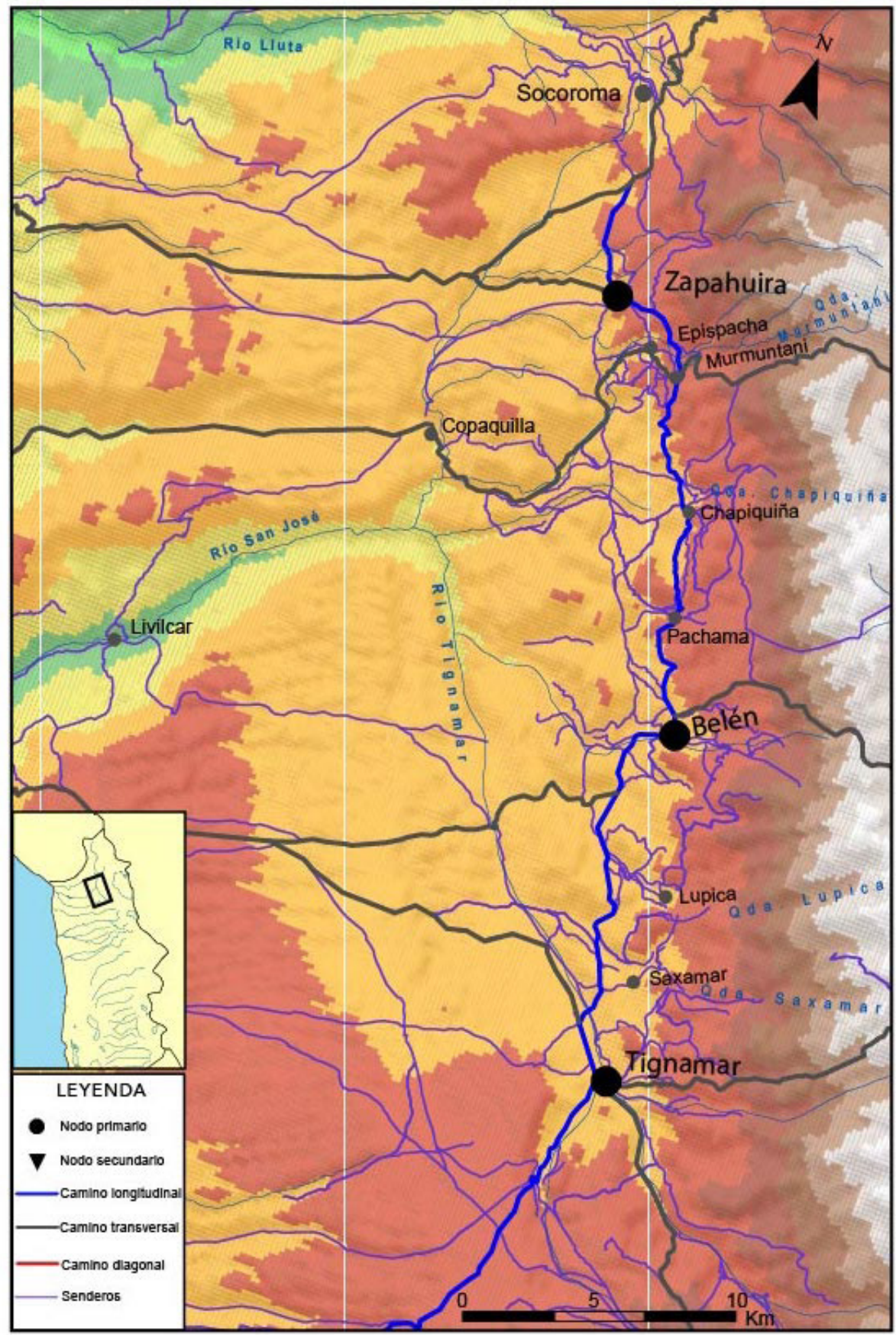

a los nodos principales, Zapahuira, Belén y Tignamar con poblados, áreas agrícolas y de pastoreo distribuidos en el sistema de quebradas que caracteriza la accidentada topografía del área (Figura 6). Las primeras incluyen complejos sistemas de andenerías y canales de carácter monumental, que la arqueología y la memoria vinculan con la producción intensiva de papas y maíz (Dauelsberg, 1983; Durston e Hidalgo, 1997; Saintenoy et al., 2017). En contraste, las áreas de pastoreo han sido escasamente estudiadas (Saintenoy et al., 2017) y se asocian a una cultura material efímera y de baja visibilidad, que se reconoce a través de asentamientos menores tipo refugios o pascanas dispersos en el espacio donde crecen los pastos de lluvia fundamentales en la ganadería indígena tradicional (Niemeyer, et al., 1971; Niemeyer, 1972; Van Kessel, 1980; Castro, 1982; González, 1997; García, 2017).
Figura 6. Red vial en el curso superior y medio de los valles de Lluta y Azapa. Fuente: elaboración propia. 


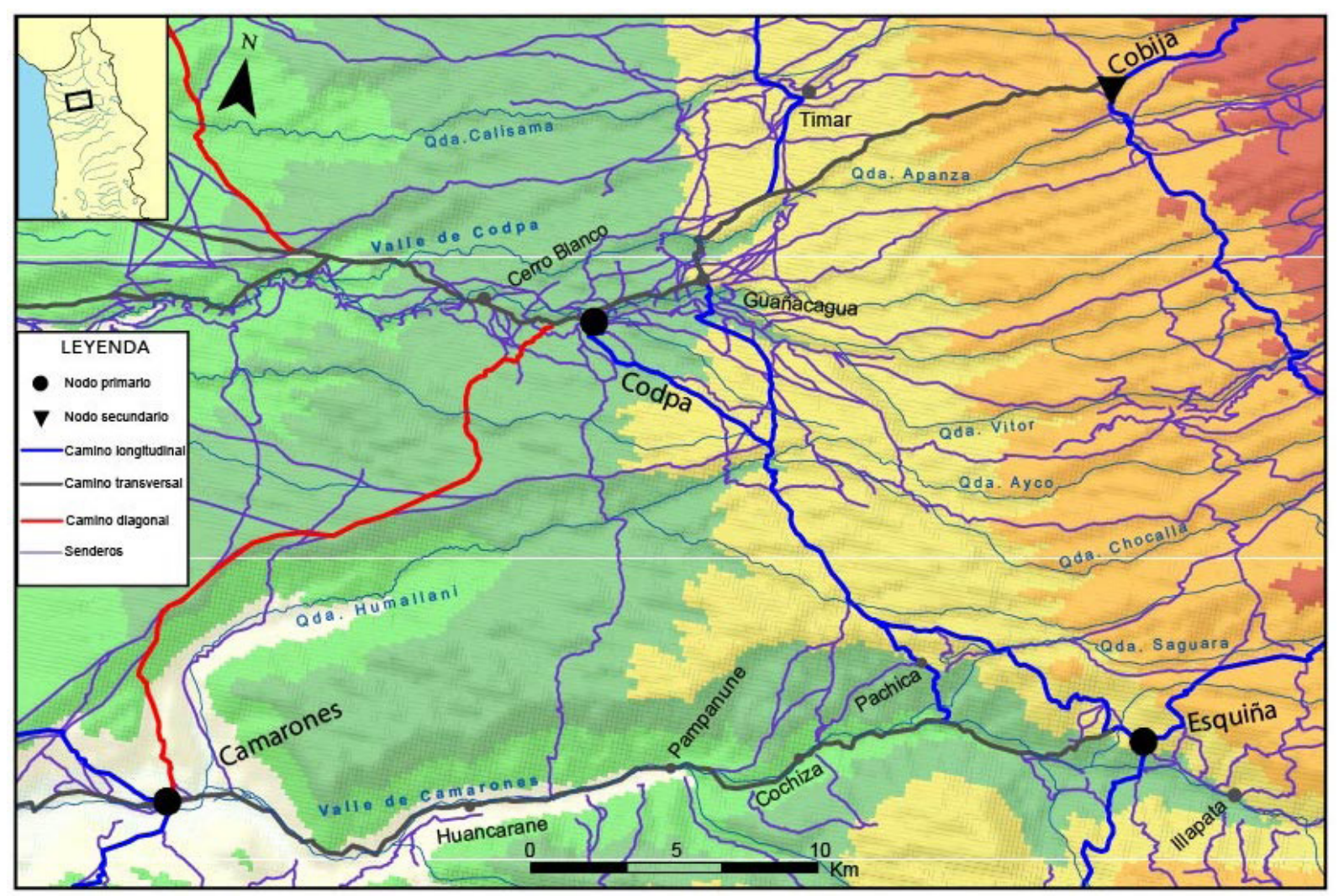

Finalmente, el tercer cuadrante con gran concentración de senderos se ubica en el curso medio y superior de los valles de Codpa y Camarones (Figura 7). Los senderos registrados atestiguan, un tránsito intenso entre Cerro Blanco, Timar, Chitita y Chocaya, siendo uno de los espacios con mayor densidad vial al interior del área de estudio. Se reconoce una configuración vial de tipo vascular que es resultado del acceso fluido a espacios productivos en el fondo del valle y quebradas aledañas, donde múltiples senderos funcionan como capilares que favorecen el acceso a los fértiles espacios del fondo de valle, mediatizado por una circulación preferente por los bordes superiores de los valles. En este espacio, los senderos conectan los valles principales con zonas de cultivo estacionales que se activan o desactivas en función a las oscilaciones de las precipitaciones estivales, como ocurre en la quebrada de Apanza o Chocaya, donde, como se verá a continuación, la etnografía registra la presencia de áreas de cultivo dependientes de los codpeños.

\section{Caminos y caminantes}

Como hemos visto, la red vial se organiza a partir de vías y nodos con distintas jerarquías, dando cuenta su estructura sobre la magnitud que alcanzaron las relaciones horizontales y verticales entre los grupos que habitaron los distintos valles y pisos ecológicos de la región. Cabe destacar que en la conformación de la red confluyen dinámicas sociales, económicas, rituales y culturales, las que estimularon el tránsito y la comunicación entre localidades. Previamente analizamos tres cuadrantes que concentran la mayor densidad de senderos, por lo que alcanzan una mayor conectividad siguiendo patrones de organización diferenciados en respuesta a condicionantes demográficas, productivas y territoriales.

A continuación, por medio de relatos etnográficos buscamos ampliar la mirada respecto a las dinámicas que sustentaron las diferentes modalidades y formas de uso de los
Figura 7. Red vial en el curso medio de los valles de Codpa y Camarones. Fuente: elaboración propia. 
caminos, principalmente a la movilidad ligada a tareas productivas y extractivas, así como a los sistemas de trueque y comercio. En este contexto, estas memorias revelan formas de ocupación del espacio que han desaparecido o están en proceso de desaparición en la actualidad, siendo un síntoma elocuente de la desestructuración territorial ocurrida durante el último siglo.

Los relatos recopilados provienen de pobladores del cuadrante Codpa-Camarones, sin embargo, tienen un alcance regional en la medida que los circuitos de movilidad sostenidos rebasaban los límites de nuestros cuadrantes que tienen un fin netamente analítico. Recordemos que en este cuadrante se reconoce un marcado patrón vascular de senderos en torno al nodo Codpa, el cual funcionó como un importante valle de orientación frutícola, la que desde la imposición colonial se centró en la producción de vino en respuesta a los intereses hispanos. En el siglo XVIII aquí fue fundado por los españoles un cacicazgo sobre asentamientos locales previos, convirtiéndose el pueblo de Codpa en uno de los principales enclaves coloniales en la sierra de Arica (Hidalgo y Durston, 1998), lo que tuvo un impacto significativo en los circuitos de tránsito.

Varios senderos comunican las distintas localidades del valle hacia el sur, con dirección a la quebrada de Chocaya. Las memorias refieren a la presencia de agricultores codpeños que mantenían cultivos en ésta, los cuales eran regados semanalmente en visitas que se hacían por el día, volviendo a dormir a su residencia principal en el valle de Codpa. En esta línea, otros autores registran traslados por parte de los agricultores codpeños señalando el "acceso a terrenos productivos en diferentes sectores de un valle o en diferentes valles y/o pisos ecológicos” (García y Romero, 2015:19).

Los registros etnográficos recopilados en los valles de Codpa y Esquiña documentan la estrecha complementariedad que existía entre ambos hasta un pasado reciente, tal como debió suceder en el cuadrante Lluta-Azapa. Sobre la base de sus características ecológicas diferenciadas, Esquiña al ser un valle salado se orienta a la producción de maíz y alfalfa, mientras que el valle dulce de Codpa se especializa en la producción de fruta.

(En) Esquiña antes, según cuentan, la mayoría de los terrenos eran de gente de más abajo, por ejemplo de Codpa, entonces ellos criaban mulares para trasladar sus cargas hacia Arica, entonces cuando no había fruta venían a dejar sus animales pa que estuvieran acá reponiéndose hasta la próxima temporada de fruta, eso es lo que se contaba (Manuel Viza, Illapata 2011).

Otra modalidad de tránsito vinculada a la producción agrícola se liga a la obtención de guano de aves costeras para abonar las chacras, movimiento que era realizado al menos una vez al año aprovechando las distintas vías transversales que se dirigen a la costa. Por ejemplo, los agricultores de la cuenca de Azapa se dirigían a las cuevas de Anzota, ubicadas al sur de la ciudad de Arica, según consta en el museo de sitio construido recientemente en el lugar. Por otra parte, en el valle de Codpa registramos un testimonio que señala viajes a la desembocadura para acceder a la guanera Ofaica, cerca de caleta Vítor, para abonar los viñedos con las cuales se producía el famoso vino Pintatani (ver también García y Romero, 2015). Por último, en Esquiña y Nama registramos viajes a las guaneras ubicadas en Pisagua Viejo, donde se menciona especialmente la guanera Española. De acuerdo a los relatos, el tiempo de viaje desde Codpa a la costa era de dos días, volviendo a la semana, yendo acompañados de cinco a diez o más burros o mulares para traer la carga de guano. En este contexto, se señala la importancia de puntos intermedios tales como Vila Vila en el valle de Chaca, Camarones o "Tambo" en el valle de Camarones, y Calatambo en el valle de Tana, todos los cuales pueden ser considerados como eventuales nodos logísticos ya que son fundamentales para el descanso y abastecimiento antes de ingresar al desierto absoluto propio de la zona costera. 
También fui a las guaneras, a varios lugares, entre Pisagua y la Caleta de Camarones. Por lo general quedaban arriba porque las guaneras estaban en el alto. Ahí no llevábamos maíz, iban las mulas vacías. Uno iba a trabajar, juntar el guano. El camino tropero está marcado, por lo menos antes, porque de todos lados iban, no solo de Esquiña, Cochiza, Camarones, de allá del lado de Camiña, Nama, por este otro lado de Tignamar, todos esos pueblos bajaban. Era pa abonar el maíz. Ese viaje se hacía una vez al año (Hernán Ñavez, Esquiña 2014).

Además del tránsito generado en torno a la producción agrícola, la etnografía señala la ocupación pastoril de las cabeceras ( $3.500 \mathrm{msnm})$ de los valles de la región, tanto en los sectores circundantes a Putre (cabecera de Lluta) como en las cabeceras de Camiña y Tarapacá (Provoste, 1976; Martínez, 1976; Castro, 1982; González, 1997). En este contexto, nuestro trabajo ha documentado el movimiento descendente de los pastores de Mulluri hacia las mesetas altas de la quebrada de Camarones, donde aprovechaban los pastizales que crecían luego de las lluvias de verano. Allí los pastores tenían sus pascanas, varias de origen prehispánico, las cuales eran ocupadas de forma itinerante siguiendo circuitos determinados por tradición familiar. Los pastores permanecían en la cabecera de Camarones por alrededor de cinco meses (marzo-agosto) hasta que se secaba el pasto y retornaban a sus estancias y pueblos ubicados en la cordillera (García, 2018). De esta forma, los circuitos de pastoreo precordilleranos también dejaron su impronta en el diseño y forma de uso de la red vial, al igual como debió suceder en la cabecera de Azapa donde se han registrado múltiples asentamientos menores vinculados con el pastoreo (Saintenoy et al., 2017). Asimismo, el trabajo etnográfico que realizamos demuestra que los mismos senderos eran usados también por otros caminantes que atravesaban los espacios de pastoreo para dirigirse a otros destinos o nodos ubicados en los valles o el altiplano.

Las modalidades de tránsito señaladas anteriormente ligadas a la agricultura y el pastoreo, a las que podemos agregar actividades de caza y recolección de plantas como yareta (Azorella compacta) para combustible (García y Romero, 2015), pueden ser expresiones de una forma dispersa de ocupación del espacio y en este sentido estar vinculadas con el llamado "acceso directo" (sensu Murra, 1972) así como con la noción de producción multicíclica (Golte, 2001), conceptos que aluden a soluciones culturales para minimizar riesgos y asegurar la reproducción humana ante la fragmentación característica de la geografía andina. En el área de estudio, esta idea fue señalada por Keller (1946) en relación a la forma de repartición tradicional de las tierras indígenas de la sierra, la cual sería una herencia de larga data.

Existen problemas de títulos de propiedad en el sector de Codpa, ya que cada vecino cultiva numerosos pequeños trozos de terreno no contiguos. En general se trata de áreas de menos de $500 \mathrm{~m}^{2}$, por lo común cada campesino tiene varios de tales pequeños predios, ubicados muchas veces a grandes distancias los unos de los otros. La superficie cultivada se compone de pequeños predios pertenecientes a un mismo dueño. (...) El reparto de esta superficie es muy parejo, disponiendo los campesinos de predios de una superficie muy similar, lo que se debe, indudablemente, al régimen imperante antes de la llegada de los españoles. (...) Existe, pues, una democracia económica casi perfecta (Keller, 1946:174-179).

Junto con las modalidades señaladas, otra dimensión fundamental del tránsito en términos etnográficos refiere a los sistemas de "acceso indirecto" a través de prácticas de trueque y comercio, los cuales, de acuerdo a la memoria oral, explican la complejidad y extensión de la red vial. Los testimonios recopilados señalan que éstos estuvieron plenamente vigentes hasta la década de 1970, momento en que la dictadura militarizó las fronteras, sembrando minas antipersonales, prohibiendo terminantemente el ingreso de extranjeros e instaurando la obligatoriedad de portar 
cédula de identidad, lo cual terminó resignificando los sistemas de tráfico tradicionales como prácticas de contrabando (Van Kessel, 1980; Pérez, 2008; Molina, 2010; García, 2015).

Los relatos etnográficos hacen referencia a diferentes formas de trueque, principalmente intercambios que realizaban, por una parte, los pastores altiplánicos con los agricultores precordilleranos, y aquél que realizaban los llamados "marchantes de Bolivia". En relación con los primeros, se señala que los viajes se realizaban de forma continua durante todo el año, aunque especialmente a partir de marzo, cuando se cosecha la fruta en Codpa y el choclo en Esquiña y Camiña, y en junio cuando está listo el maíz seco. Un ejemplo es el traslado de los pastores de Mulluri hacia dichos valles con carne fresca o animales vivos para carnear, lo que demandaba una jornada de camino (8 a 12 horas). Salían de madrugada, especialmente para los valles de Esquiña, Nama y Camiña donde usualmente participaban en fiestas religiosas y visitaban a sus parientes. En cambio, se señala que los vínculos con Codpa buscaban la adquisición de fruta y vino, ya que prácticamente no hay menciones de relaciones de parentesco.

La gente de Mulluri iba varias veces al año a los valles. Venían a Esquiña a cambiar maíz, cambiaban con carne, charqui, queso. También a Codpa se cambiaba la uva, la pera, el vino. Todas esas cosas se llevaban. Por ser, los de Parcohaylla bajaban con la lana a Camiña, se cambiaba. Ahora quiere maíz, ahí tiene que venir a Esquiña a cambiar con carne y ya sacas maíz también. Eso era antes po... También el algodón acá se usaba mucho para hacer lámpara, alumbrao. En Esquiña había matitas (Emilia García, Mulluri 2015).

Un día completo era de Esquiña hasta Mulluri. Con mulo, mi papá venía a buscar con burro, yeguas venía, eso. Pero uno caminando más rápido iba porque así cortando camino. Siempre traía tres animales, uno de carga y otro para él y otro para mi, la yegua. Mataba animales acá, llevaba carne, de Esquiña el maíz. Ellos lo guardaban en trojas bajo la tierra, ahí se mantenía como medio año yo creo. En sacos traían para acá mucho. También hacían cambio de carne por maíz. Justamente era $1 \times 2$. Por ejemplo, 10 kg de carne por 20 de maíz, así era el trueque (Javier Flores, Mulluri 2015).

No obstante, a los valles no solamente llegaban los pastores de Mulluri a adquirir maíz, sino que también lo hacían pastores de otras comunidades de la región Carangas. Pobladores ancianos del valle de Codpa y de Esquiña recuerdan que venían pastores desde Guallatire, Surire e Isluga en territorio chileno y del lado boliviano comunidades distantes como Sajama, Chachacumane, Cosapa, Laguna, Sajama, Corque, Sacabaya, Huachacalla, Sabaya, entre otros. Asimismo, comúnmente se hace referencia a los marchantes de Bolivia que, si bien se tienden a homologar con los pastores anteriores, hay relatos que los identifican como especialistas del tráfico o comerciantes. En este sentido, junto con los productos propios de las economías domésticas de los pastores como carne, charqui, papa, chuño, quinua, también comerciaban harinas, sal, remedios, frutas, copal, incienso, incluso velas y radios a pila.

Este maíz la gente venía a llevarse, pero no llevaban poco, llevaban 40, 50 llamos cargados. Cada llamo cargado 20 kilos, 30 kilos, ¿ese sabes pa cuándo? se cambiaba pa tiempo de lluvia, para pasar enero, febrero, marzo, porque en ese tiempo ya no pueden caminar por la lluvia. Este tiempo [julio] están llegando de allá iitropas, tropas, todos los días!! Harta gente, tres, cuatro personas con tropas de cincuenta, sesenta animales; de Bolivia traían papas, cuarenta, cincuenta llamos cargados de papas, y de acá también se llevaban maíz. Traían las frazadas, a veces también ropas, pantalones, en esos años ellos hacían, aquí la gente compraba, así como en el tiempo de los gentiles... Pero eso murió, nadie viene, y nadie va (Eugenio Apata, Esquiña 2011). 


\begin{abstract}
Venían los marchantes de Bolivia con llamos cargados, traían charqui, papa, chuño, no usaban mulares esa gente usaba llamos y burros. Ellos venían de Bolivia, de allá de Todos los Santos, de Carangas, de Rivera, de Huachacalla. Se alojaban en los corrales más que nada, por ahí nomás. Cambiaban ellos con lana de alpaca, Ilamo, cordero, lana, así era antes. Hablaban aymará, como los viejos antiguos entendían aymará.... del 99094 todavía andaban bolivianos por acá. Con llamos cargados más antes, sería como el 72, 74 por ahí venían mucho con llamo. Después dejaron. Después del 94 al 2001 venían con puro burro (David Aranibar, Mulluri 2016).
\end{abstract}

¡Vimos los llamos cargados! 20, 30 llamos. Traían charqui, sal, chuño, papa traían. Pa' hacer cambalache con el maíz. Y nosotros entregábamos la lana y nos traían mercadería de Bolivia, pa' hacer comercio pa' venderlo pallá. Fruta no traían. Pasaban por Mulluri a Camiña a llevar el maíz, a hacer un cambalache, como se produce tanto maíz. Llegaban a Codpa y se llevaban fruta también. Los bolivianos andaban por todo camino iigual que carreteras! En las apachetas era una costumbre que tenían ellos pa' dejar el cansancio, la enfermedad. Cuando viajaban hacían montoncitos de piedra para que los animalitos vuelvan bien cargados y dejaban sus montones de piedra, y también dejaban plata. En la apacheta de piedra tenían sus casilleritos y ahí dejaban plata. Ahí fumaban cigarrito, dejaban todo eso. ¡El tráfico era grande! Llegaban todo el año completo. Se cruzaban igual que los vehículos, uno está bajando y al otro día está subiendo. Dos, tres personas con su tropa. Ahora no hay nada está todo perdido. Hace 50 años será. En ese tiempo la coya valía más. La coya [Diplostephium cinereum] valía como $4 \mathrm{~kg}$ de mercadería, una chipa. De azúcar, o chuño o lo que tenían ellos (Raúl Mamani y Demetrio García, Mulluri 2016).

A través de la región, una de estas rutas empleadas por los marchantes de Bolivia, recorría a través de Sabaya - Rivera - Todos los Santos - Cerro Capitán (hito fronterizo Bolivia-Chile) - Salar de Surire, y desde allí se abrían tres descuelgues alternativos: Mulluri - Camiña, Mulluri - Esquiña - Codpa, y Parcohaylla - Umirpa - Ayco - Codpa.

Este tráfico a larga distancia ha sido ampliamente descrito en la literatura etnográfica, donde se hace referencia a estos marchantes como "llameros" o "fleteros", señalando la importancia que tenían estos viajes hacia los valles del Pacífico, vinculándose a la noción de caravaneros (Flores, 1975; Provoste, 1976; Rivière, 1979, 1982; Lecoq, 1987; Nielsen, 1997). En el caso de los pastores del Cuzco, los productos obtenidos por los pastores en los valles (papas, maíz y cereales) eran usados en la década de 1970 para alimentar a sus familias, financiar sus aynis, continuar la producción, pagar los precios de los cargos públicos y solventar las estas (Custred, 1977). Finalmente, los llameros han sido descritos como genuinos agentes sociales, culturales y económicos, que articularon vastas regiones y subregiones (Concha, 1975).

Por distintos requerimientos logísticos, esta movilidad a larga distancia debió concentrarse en ciertas estaciones del año, especialmente entre los meses de marzo y mayo, una vez nalizada la temporada de cosecha y cuando hay disponibilidad de pastos de lluvia para las llamas cargueras (Lecoq, 1987; Tomoeda, 1988). Asimismo, en el norte de Chile la literatura también indica que la principal época de intercambios coincidía con el tiempo en que los pastores de Mulluri, Isluga y Cariquima se encontraban pasteando su ganado en la precordillera (marzo-agosto), período que además concentra la mayoría de las festividades religiosas de los pueblos ubicados en las quebradas adyacentes (Martínez, 1976; Provoste, 1976; van Kessel, 1980; Gavilán y Carrasco, 2009; Urrutia, 2011; García, 2018).

Complementariamente, la producción en el mundo andino está íntimamente ligada a la ritualidad propiciatoria, particularmente la fecundidad agrícola y ganadera. Ésta se 
define a partir de una serie de prácticas socialmente pautadas y arraigadas en el sistema de creencias de las comunidades. Estas instancias son inseparables de las relaciones culturales y sociales, las que propician la integración de poblados mediante vínculos familiares, étnicos, identitarios y territoriales. En este contexto, diversas instancias festivas se relacionan con el traslado de personas entre pueblos para asistir a estas fiestas (devotos, músicos), en las que están involucrados distintos traslados como el acceso a espacios rituales en la cumbre de cerros, calvarios y cruces, donde se superponen costumbres y creencias indígenas y católicas. Así, las poblaciones se interrelacionaron de forma dinámica, dependiente de su devenir histórico y del establecimiento de vínculos y compatibilidad entre comunidades, siendo las instancias del calendario festivo donde este tipo de relaciones se manifiesta con mayor intensidad (Urzúa, 1957; Ruz et al., 2011; García, 2015).

En suma, entendemos que tras la movilidad de las poblaciones locales subyacen intereses múltiples, que se expresan en diferentes modalidades de interacción y tránsito. En este marco, no cabe duda que el tránsito de caravanas de llamas trasladando productos entre distintos ambientes alcanzó importancia y centralidad, pero no hay que olvidar que operó en paralelo a otras modalidades. Por esta razón, es esperable que el tránsito pedestre sin apoyo de animales (llamas, mulares), o bien acompañado éstos en trayectos de corto y mediano alcance, se hubiera realizado de manera frecuente dando respuesta a distintas necesidades.

\section{Conclusiones}

Hemos expuesto la estructuración de la red vial en función de caminos troncales, senderos y nodos, cruzando esta información con relatos etnográficos sobre distintas modalidades de tránsito. Recapitulando, los senderos denotan un tránsito descentralizado relacionado al acceso fluido a lugares a corta y mediana distancia, pudiendo operar a modo de descuelgues o enlaces con caminos troncales, o bien como vías directas entre localidades próximas. Señalan con claridad las diferentes dimensiones y modalidades de transito ligada a lo productivo, extractivo, ceremonial y festivo, permitiendo acceder a la movilidad ligada a grupos agricultores, que usualmente se han asumido como grupos de baja movilidad. Se incluyen prácticas como el acceso directo producciones complementarias, la multi residencia, relaciones intergrupales de tipo colaborativo y festivo, intercambio directo entre productores y comercio.

Los caminos troncales, en cambio, tienden a concentrar los flujos de tránsito, estableciendo enlaces viales entre nodos por lo que centralizan la movilidad de personas y recursos. Si bien en estos confluyen tránsitos de distinto alcance, el tránsito a larga distancia circula preferentemente por estos caminos, incluyendo además los circuitos cortos y medianos. En esta línea, los caminos troncales se asocian a una mayor diversidad de modalidades de tránsito incluyendo lo descrito para los senderos, así como el tráfico especializado de productos mediante el uso caravanas conocidos como llameros, fleteros o caravaneros (Flores, 1975; Núñez 1976, 1984; Lecoq, 1987; Nielsen, 1997). Por ende, desde una perspectiva de larga duración, los caminos troncales son más propensos a los cambios al ser receptivos de un tránsito foráneo.

En suma, la distribución de caminos troncales, senderos y nodos, dan cuenta de la gran magnitud que alcanzaron las relaciones horizontales entre los distintos valles bajos, que son relativamente abiertos en comparación con el encajonamiento característico que estos adquieren en su ascenso hacia tierras altas. Este tipo de relaciones espaciales, como las documentadas en el cuadrante de la cuenca inferior de Lluta y Azapa con un patrón con conectividad interfluvial intensa y fluida, son prácticamente invisibles bajo 
una lógica vertical donde el foco de las interpretaciones se concentra en el binomio altiplánico-pastor / valluno-agricultor. En esta misma línea, el componente estrictamente costero ha tendido a asumirse como compuesto por grupos territorialmente confinados al litoral, y por ende dependientes de los movilizadores del tráfico de larga distancia (cfr. Pimentel et al., 2011).

En relación a los cuadrantes analizados, en la cabecera del valle de Azapa también se gestó una alta densidad demográfica. Allí la organización productiva responde a condiciones geográficas de baja puna donde se combina una producción agrícola asociada a sistemas agro hidráulicos, con una actividad ganadera que aprovecha los recursos forrajeros de la sierra (pastos de lluvia) -tan subvalorados por la arqueología local como las movilidades horizontales- y del altiplano, a los cuales se tiene un acceso directo. Esta orientación productiva agro ganadera se asocia a un patrón vial propio donde no reconocemos una direccionalidad predominante como consecuencia de la yuxtaposición de modalidades de tránsito diversas que responden a distintos intereses. Aquí predomina un tránsito relacionado a la ocupación intensiva de recursos entre los 2.800 y $3.600 \mathrm{~m}$. de altura, desplegándose un camino troncal longitudinal (camino Precordillerano) y un entramado multidireccional de senderos, junto a cuatro caminos troncales alternativos para el descenso a los distintos valles bajos y el acceso al altiplano (Caquena, Parinacota, Lauca y Guallatire).

Por su parte, Azapa y Lluta centralizan gran parte de la movilidad de los Valles Occidentales meridionales. Si bien ambas cuencas cuentan con una historia ocupacional muy diferente, la evidencia vial apunta a una organización compartida, lo que puede referir a un desarrollo interdigitado entre las comunidades de ambos valles aprovechando sus condiciones dulces y saladas que favorecen producciones agrícolas diferentes y complementarias.

Por su parte, la alta densidad vial en el curso medio y superior de Codpa y Camarones, se organiza en función de las producciones agrícola y agro pastoril. A esta altura los valles están encajonados en profundos cañadones y su potencial agrícola es más restringido que en los valles bajos de más al norte. A su vez, la conectividad fluida con los espacios de baja puna al sur del cerro Marquéz explica la configuración mixta de caminos y senderos. Observamos que por un lado el tránsito agrícola -especialmente bajo los $3.000 \mathrm{msnm}$ - tiende a una organización vascularizada para acceder desde el fondo del valle a los caminos troncales que circulan por los altos, mientras que el tránsito agro pastoril -sobre los $3.000 \mathrm{msnm}$ - genera enlaces fluidos y alternativos transversales hacia las áreas de pastoreo que se despliegan en el borde occidental de la Sierra de Huaylillas.

Por lo tanto, la organización de la red vial de la región de Valles Occidentales establece un diálogo fluido con el espacio físico, la distribución de los recursos y los asentamientos humanos. La Cordillera de la Costa, la Sierra de Huaylillas y la Cordillera Central son accidentes geográficos que moldean el espacio y generan un escalonamiento altitudinal abrupto, favoreciendo la distribución de un amplio espectro de recursos y condiciones ambientales diferenciadas por pisos ecológicos. A su vez, es innegable la particularidad que aportan los ríos Lluta, Azapa, Chaca, Camarones y Tana. Estas cinco cuencas moldean el territorio regional, segmentando la Depresión Intermedia y la Cordillera de la Costa, y albergando un sistema de poblados que dialoga con el territorio y sus recursos, desplegando una organización productiva relacionadas a estos factores.

En consecuencia, el área de estudio se compone de una serie de espacios productivos que conforma un rico mosaico de recursos. La orografía del territorio no fue obstáculo para su aprovechamiento, imponiendo la necesidad de desarrollar un sistema de movilidad que favoreciera la apropiación productiva y simbólica de territorios disímiles pero 
integrados en un paisaje cultural (Castro et al., 2004) cargado de elementos significativos (Briones y Mondaca, 2004; García, 2015). De esta forma, las vías de comunicación están implicadas en requerimientos logísticos de una comunidad siendo parte de su infraestructura productiva.

Los tres espacios descritos forman parte de una territorialidad indígena internamente diferenciada por formas de concebir el espacio, de habitarlo; de generar sistemas de apropiación, producción de recursos, y una compleja red de relaciones entre comunidades. En suma, la conformación de la red vial se integra a los patrones de asentamiento, en cuanto construcción dialéctica del territorio y los grupos sociales que lo habitan. La capacidad moldeadora de uno y otro se evidencia en la organización de una entidad sociopolítica que integró en el pasado el área de estudio, así como en la adaptación de la misma a las condiciones de la naturaleza apropiada. En este contexto los caminos se yerguen como productores y referentes de espacialidad, de un espacio que entendemos como un producto social. De esta manera, el análisis vial revela una territorialidad indígena dispersa relacionada a patrones de asentamiento dinámicos donde la gente mantiene varias residencias simultáneas en distintas jerarquías.

Desde los relatos etnográficos se ha descrito una amplia gama de modalidades que enriquece la mirada de la movilidad a partir de propósitos múltiples. Esto permite descentrar el modelo caravanero, visibilizando una importante diversidad de formas que manifiestan la intensa conectividad espacial. Estas movilidades incluyen distintas alternativas que, a diferencia del caravaneo de larga distancia, por su alcance y escala se debieron desarrollar con requerimiento logísticos flexibles y una planificación más sencilla.

El sistema de caminos troncales propuesto efectivamente puede asimilarse al escenario vial caravanero, aunque destacamos que estas rutas fueron ocupadas bajo distintas modalidades de tránsito. Estas incluyen, por cierto, a caminantes que realizan circuitos sin apoyo de animales de carga o solo un par. En este contexto hemos querido ampliar la discusión sobre la movilidad, usualmente asignada a las poblaciones altiplánicas, explorando las modalidades de grupos agricultores y agroganaderos, haciendo notar que el foco de las investigaciones sobre movilidad y complementariedad se han obcecado en discutir el caravaneo y los contactos costa - selva, invisibilizando las soluciones cotidianas que requieren de una logística sencilla y se realizan de manera fluida. Más allá de una idealización del viaje a largo del transecto andino (sensu Núñez y Dillehay, 1995), es clave repensar los desplazamientos en trayectos de corto y mediano alcance, los cuales pueden tener trayectorias longitudinales, transversales o diagonales relacionadas con la conectividad entre valles y pisos alternados. Por tanto, los resultados obtenidos permiten descentrar la hegemonía de los movimientos verticales, demostrando la importancia de los movimientos horizontales y diagonales.

La red vial acusa la intervención de múltiples dinámicas de movilidad que rebasan el poder explicativo de la Movilidad Giratoria, particularmente por su énfasis en las caravanas de llamas como una empresa que acapara la mayor parte de los desplazamientos de recursos y, de alguna manera, sería la respuesta al problema de la complementariedad andina, dejando a las poblaciones de los valles como entes pasivos que dependen de soluciones logísticas que les son ajenas. Por ende, para generar una visión integral de la integración territorial, debemos pensar al sistema de caravanas funcionando en paralelo a otras estrategias para así entender que la movilidad no se circunscribe en circuitos horizontales - verticales, tratándose más bien de una movilidad generalizada y profundamente interconectada.

En definitiva, la yuxtaposición caminera es un concepto inmanente que actúa en distintas dimensiones, erigiéndose como un trasfondo epistémico relevante para pensar los caminos en cuanto materialización de prácticas de movilidad heterogéneas que 
convergen en un mismo sistema caminero. En este sentido, junto con la superposición de materiales debido al uso reiterado en el tiempo, la yuxtaposición incluye elementos significativos como las toponimias, saberes, la infraestructura asociada a las vías, modalidades y propósitos del tránsito, alcances y logística de los movimientos. Por tanto, ésta va más allá de una concepción diacrónica de los caminos y busca comprender aspectos relacionados con la construcción de los paisajes, a nuestras formas presentes de movernos en ellos y a las complejas cargas de significados que rodean y los envuelven. Por esto los caminos son a su vez potentes dispositivos de memoria al remitirnos a circuitos de movilidad ancestral donde se cruzan las distintas capas de significado yuxtapuestas en la red vial en cuanto sistema total de tránsito, así como en los nodos y trayectos de senderos, caminos y troncales que son los elementos centrales que la componen.

\section{Agradecimientos}

Agradecemos a los editores de este volumen por acoger nuestra propuesta y a los evaluadores anónimos por sus comentarios y sugerencias que sirvieron para mejorar significativamente este trabajo. Al financiamiento aportado por CONICYT, a través de Becas Chile (Magister y Doctorado en el extranjero), Beca de Doctorado Nacional y los proyectos PIA Anillo SOC1405 "Cambios Sociales y Variabilidad Climática a Largo Plazo en el Desierto de Atacama”, Fondecyt 1130279 y PCI PII20150081. A la comunidad indígena de Mulluri y a los pobladores de los valles de Esquiña, Codpa y Nama que aportaron con sus memorias dando cuerpo a esta investigación. A Tania Muñoz y Rolando Ajata por su apoyo en el trabajo de campo y a Claudia Aranda por las correcciones del abstract. 


\section{Q Bibliografía}

» ALDUNATE, Carlos, CASTRO, Victoria y VARELA, Varinia (2003) Oralidad y arqueología: una línea de trabajo en las tierras altas de la Región de Antofagasta. Chungara, 35(2), pp. 305-314.

" ALISTE, Enrique y NúÑEZ, Andrés (2015) Las fronteras del discurso geográfico: el tiempo y el espacio en la investigación social. Chungara, 47(2), pp. 287-301.

»ALVAREZ, Luis (1991) Etnopercepciones andinas: Valles dulces y salados en la vertiente occidental de los Andes. Diálogo Andino, 10, pp. 9-19.

» BALLESTER, Benjamín, y GALLARDO, Francisco (2011) Prehistoric and historic networks on the Atacaman Desert coast (northern Chile). Antiquity, 85(329), pp. 875-889.

»BERENGUER, José (2002) Tráfico de caravanas, interacción interregional y cambio cultural en la preshitoria tardía del Desierto de Atacama. (Tesis doctoral). University of Illinois at Urbana-Champaign.

» BERENGUER, José, CÁCERES, Iván, SANHUEZA, Cecilia y HERNÁNDEZ, Pedro (2005) El Qhapaqñan en el Alto Loa, norte de Chile: Un estudio micro y macromorfológico. Estudios Atacameños, 29, pp. 7-39.

» BERENGUER, José, SANHUEZA, Cecilia, y CÁCERES, Iván (2011) Diagonales incaicas, interacción interregional y dominación en el altiplano de Tarapacá, norte de Chile. En: Núñez, L. y Nielsen, A. (Eds.), En ruta. Arqueología, historia y etnografía del tráfico sur Andino. Córdoba: Editorial Brujas, pp. 247-283.

"BRIONES, Luis y MONDACA, Carlos (2004) Rutas de tráfico y representaciones rupestres de la quebrada de Suca: una interacción geocultural andina milenaria. Diálogo Andino, 24, pp. 99-113.

» BRIONES, Luis, NÚÑEZ, Lautaro y STANDEN, Vivien (2005) Geoglifos y tráfico prehispánico de caravanas de llamas en el Desierto de Atacama (norte de Chile). Chungara, 37(2), pp. 195-223.

»CASTILLO, Camila y SEPúLVEDA, Marcela (2017). Objetos “misceláneos” y dinámicas sociales en contextos cazadores recolectores de la precordillera de Arica, extremo norte de Chile. Chungara, 49(2), pp. 159-174.

»CASTRO, Milka (1982) Estrategias socioculturales de subsistencia en las comunidades alto andinas en el interior de la provincia de Arica. En: Veloso, A. y Bustos, E. (Eds.) El hombre y los ecosistemas de montaña. Vol. II. Montevideo: Programa MAB-6, UNESCO, pp. 99-132.

"CASTRO, Victoria, ALDUNATE, Carlos y VARELA, Varinia (2012) Paisajes Culturales de Cobija, Costa de Antofagasta, Chile. Revista de Antropología, 26(2), pp. 97-128.

»CASTRO, Victoria, VARELA, Varinia, ALDUNATE, Carlos y ARANEDA, Edgardo (2004) Principios orientadores y metodología para el estudio del Qhapaqñan en Atacama: Desde el Portezuelo del Inka hasta Río Grande. Chungara, 36(2), pp. 463-481.

»CHOQUE, Carlos, y MUÑOZ, Iván (2016) El camino real de la plata: Circulación de mercancías e interacciones culturales en los valles y Altos de Arica (siglos XVI al XVIII). Historia, 49(1), pp. 57-86. 
»CONCHA, Juan (1975) Relación entre pastores y agricultores. Allpanchis, 8, pp. 67-101.

» CUSTRED, Glynn. (1977) Las punas de los Andes centrales. En: J. Flores (ed.) Pastores de puna. Uywamichiq punarunakuna. Lima, Perú: Instituto de Estudios Peruanos, pp. 55-86.

»DOLLFUS, Olivier (1981) El reto del espacio andino. Perú Problema. Lima: Instituto de Estudios Peruanos.

»DURSTON, Alan e HIDALGO, Jorge (1997) La presencia andina en los valles de Arica, siglos XVI-XVIII: casos de regeneración colonial de estructuras archipielágicas. Chungara, 29(2), pp. 249-273.

» FÁBREGA, Pastor. (2004) Poblamiento y territorio de la Cultura Castreña en la comarca de Ortegal. Capa 19, pp. 9-61.

"FLORES, Jorge (1975) Pastores de alpacas. Allpanchis, 8, pp. 5-23.

" GALLARDO, Francisco (2013) Sobre el comercio y mercado tradicional entre los Lupaca del Siglo XVI: un enfoque económico sustantivo. Chungara, 45(4), pp. 599-612.

» GARCÍA, Magdalena (2015) Movilidad y territorio en la precordillera de Camarones. Un estudio desde los caminos troperos. (Tesis para optar al grado de Magister en Antropología). Universidad de Tarapacá; Universidad Católica del Norte.

" GARCÍA, Magdalena (2018) Otra costa hay en la puna. Memorias y materialidad de un espacio pastoril en la sierra de Arica-Tarapacá, Andes del norte de Chile (ca. 2.600-4.00o msnm). Tesis para optar al grado de Doctora en Antropología, Universidad Católica del Norte-Universidad de Tarapacá.

» GARCÍA, Magdalena y AJATA, Rolando (2016) Arqueología y memoria de los caminantes de la precordillera de Camarones, sierra de Arica. Diálogo Andino, 49, pp. 235-248.

» GARCÍA, Pablo y ROMERO, Álvaro (2015) Arrieraje Andino en la región de Arica y Parinacota. Arica.

» GAVILÁN, Vivian y CARRASCO, Ana María (2009) Festividades andinas y religiosidad en el norte Chileno. Chungara, 41(1), pp. 101-112.

» GOLTE, Jürgen (2001) Cultura, racionalidad y migración andina. Lima: Instituto de Estudios Peruanos.

» GONZÁLEZ, Héctor (1997) Economía y uso del espacio en la sociedad aymara actual. En: Actas Segundo Congreso Chileno de Antropología, Vol. 2. Santiago: Colegio de Antropólogos de Chile, pp. 567-579.

" GONZÁLEZ, Héctor, GUNDERMANN, Hans y HIDALGO, Jorge (2014) Comunidad indígena y construcción histórica del espacio entre los aymara del norte de Chile. Chungara 46(2), pp. 233-246.

" HERNANDO, Almudena (1995) La Etnoarqueología, hoy: una vía eficaz de aproximación al pasado. Trabajos de Prehistoria, 52(2), pp. 15-30.

" HIDALGO, Jorge y DURSTON, Alan (1998) Reconstitución étnica colonial en la Sierra de Arica: El Cacicazgo de Codpa, 1650-178o. En: Actas del IV Congreso Internacional de Etnohistoria, Vol. 2. Lima: Pontificia Universidad Católica del Perú, pp. 32-75.

» HIDALGO, Jorge, MARSILLI, MaríayAREVALO, Patricia(1991)Complementariedad andina y la expansión de las haciendas en el valle de Lluta y la sierra de Arica: 1730-1838. En: Actas del XI Congreso Nacional de Arqueología Chilena, pp. 31-40. 
» INAMURA, Tetsuya (1988) Relación estructural de pastores y agricultores en las fiestas religiosas de un distrito. En: Flores, J. (Ed.), Llamichos y paqocheros: pastores de llamas y alpacas. Cuzco: Centro de Estudios Andinos, pp. 203-214.

» INGOLD, Tim (1993) The temporality of Landscape. World Archaeology, 25(2), pp. 152-174.

"KELLER, Carlos (1946) El Departamento de Arica. Santiago de Chile: Zig-Zag.

»VAN KESSEL, Juan (1980) Holocausto al progreso: los aymaras de Tarapacá. Centrum voor Studie en Documentarie van Latijns-Amerika.

» LATORRE, Claudio, SANTORO, Calogero, UGALDE, Paula, GAYÓ, Eugenia, OSORIO, Daniela, SALAS, Carolina (2013) Late Pleistocene human occupation of the hyperarid core in the Atacama Desert, northern Chile. Quaternary Science Reviews, 77, pp. 19-30.

» LECOQ, Patrice (1987) Caravanes de lamas, sel et échanges dans une communauté de Potosí, en Bolivie. Boletín del Instituto Francés de Estudios Andinos, 16, pp. 1-38.

» LEFEBVRE, Henri (1974) La producción del espacio. Papers: revista de sociología, 3, pp. 219-229.

» LUMBRERAS, Luis (1981) Arqueología de la América andina. Lima, Perú: Milla Batres.

" MARTíNEZ, Gabriel (1976) El sistema de los Uywiris en Isluga. En: Niemeyer, H. (Ed.), Homenaje al Dr. Gustavo Le Paige, S. J. Antofagasta: Universidad del Norte, pp. 255-328.

» MENDEZ-QUIROS, Pablo (2016) Redes viales e integración territorial en los Valles Occidentales, área Centro Sur Andina. (Trabajo Final conducente al grado de Master en Arqueología Prehistórica). Universidad Autónoma de Barcelona.

» MOLINA, Raúl (2010) Collas y atacameños en el desierto y la puna de Atacama y el valle de Fiambalá. Tesis Doctoral, Universidad de Tarapacá-Universidad Católica del Norte.

» MOSTNY, Grete (1959) La momia del cerro El Plomo. Boletín del Museo Nacional de Historia Natural, XXVII, pp. 3-119.

» MUÑOZ, Iván y BRIONES, Luis (1996) Poblados, rutas y arte rupestre precolombinos de Arica: descripción y análisis de sistema de organización. Chungara, 28(1/2), pp. 47-84.

" MURRA, John (1972) El “control vertical” de un máximo de pisos ecológicos en la economía de las sociedades andinas. En: Visita de la Provincia de León de Huánuco (1562) / por Iñigo Ortiz de Zúñiga, visitador. Universidad Hermilio Valdizán, pp. 439-476.

» NIELSEN, Axel (1997) El tráfico caravanero visto desde la jara. Estudios Atacameños, 14, pp. 339-371.

» NIEMEYER, Hans (1972) Las pinturas de la sierra de Arica. Editorial Gerónimo de Bibar, Editorial Universitaria, Santiago.

» NIEMEYER, Hans, SCHIAPPACASSE, Virgilio y SOLIMANO, Iván (1971) Padrones de poblamiento en la Quebrada de Camarones (Provincia de Tarapacá). Estudio preliminar que comprende el Sector Medio y Superior del valle. En: Acta del VI Congreso de Arqueología Chilena. Universidad de Chile., pp. 115-137.

» NúÑEZ, Lautaro (1976) Geoglifos y tráfico de caravanas en el desierto chileno. En: Niemeyer, H. (Ed.), Homenaje al Dr. Gustavo Le Paige, S. J. Antofagasta: Universidad del Norte, pp. 147-201. 
» NúÑEZ, Lautaro (1984) Tráfico de complementariedad de recursos entre las tierras altas y el Pacífico en el Área Centro Sur Andina. (Tesis doctoral). Universidad de Tokio.

» NÚÑEZ, Lautaro y DILLEHAY, Tom (1995) Movilidad giratoria, armonía social y desarrollo en los Andes meridionales: patrones de tráfico e interacción económica. Antofagasta: Universidad del Norte.

"PÉREZ, Camila (2008) Transformaciones alimentarias en la localidad de Guañacagua, valle de Codpa. Tesis de Título en Antropología, Universidad Bolivariana.

» PIMENTEL, Gonzalo (2012) Redes viales prehispánicas en el Desierto de Atacama. Viajeros, Movilidad e Intercambio. (Tesis Doctoral). Universidad Católica del Norte y Universidad de Tarapacá.

» PIMENTEL, Gonzalo, REES, Charles, DE SOUZA, Patricio y ARANCIBIA, Lorena (2011) Viajeros costeros y caravaneros. Dos estrategias de movilidad en el período Formativo del Desierto de Atacama, Chile. En: Núñez, L. y Nielsen, A. (Eds.), En ruta. Arqueología, historia y etnografía del tráfico sur Andino. Córdoba: Editorial Brujas, pp. 43-81.

»Provoste, Patricia (1976) Antecedentes de la estructura socioeconómica de Isluga. Centro de Investigaciones Isluga, Universidad del Norte, Iquique.

» RICHARD, Nicolás, MORAGA, Jorge y SAAVEDRA, Adrián (2017) El camión en la Puna de Atacama (1930-1980): mecánica, espacio y saberes en torno a un objeto técnico liminal. Estudios atacameños, 52, pp. 177-199.

» RIVIÈRE, Gilles (1979) Intercambio y reciprocidad en Carangas. Antropología, 1, pp. 85-113.

» RIVIÈRE, Gilles (1982) Sabaya, structures socio-économiques et représentations symboliques. Tesis Doctoral, École des Hautes Études en Sciences Sociales (EHESS).

»ROSTWOROWSKI, María (1977) Etnia y sociedad: costa peruana prehispánica. Lima, Perú: Instituto de Estudios Peruanos.

»RUZ, Rodrigo, DíAZ, Alberto y FUENTES, Rodrigo (2011) Timalchaca. Fiesta, tradición y costumbre en el Santuario de la Virgen de los Remedios. Arica, CONADI.

"SAINTENOY, Thibault, AJATA, Rolando, ROMERO, Álvaro y SEPÚLVEDA, Marcela (2017) Arqueología del territorio aldeano prehispánico tardío en los Altos de Arica: aportes de la fotointerpretación satelital para el estudio regional de la cuenca alta de Azapa. Estudios Atacameños, 54, pp. 85-110.

» SALOMON, Frank (1985) The dynamic potential of the complementarity concept. En: Masuda, S., Shimada, I. Morris, C. (Eds.), Andean Ecology and Civilization: An Interdisciplinary Perspective on Andean Ecological Complementarity. Tokyo: University of Tokyo Press, pp. 511-532.

» SANTORO, Calogero (1983) Camino del Inca en la sierra de Arica. Chungara, 10, pp. 47-56.

» SANTORO, Calogero y CHACAMA, Juan (1982) Secuencia cultural de las tierras altas del área Centro Sur Andina, Chungara, 9, pp. 22-45.

»SANTORO, Calogero, DILLEHAY, Tom, HIDALGO, Jorge, VALENZUELA, Daniela, ROMERO, Álvaro, ROTHHAMMER, Francisco y STANDEN, Vivien (2010) Revisita al tercer caso de verticalidad de John Murra en las costas de los Andes Centrales y Centro Sur. Chungara, 42(1), pp. 325-340. 
» SANTORO, Calogero, ROMERO, Álvaro, STANDEN, Vivien y VALENZUELA, Daniela (2009) Interacción social en los períodos Intermedio Tardío y Tardío, Valle de Lluta, Norte de Chile. En: Topic, J. (Ed.) La arqueología y la etnohistoria: un encuentro andino. Lima: Instituto de Estudios Peruanos, pp. 81-136.

" SANTORO, Calogero, UGALDE, Paula, LATORRE, Claudio, SALAS, Carolina, OSORIO, Daniela, JACKSON, Donald y GAYÓ, Eugenia (2011) Ocupación humana pleistocénica en el Desierto de Atacama: Primeros resultados de la aplicación de un modelo predictivo de investigación interdisciplinaria. Chungara, 43(esp.), pp. 353-366.

" THOMAS, Julian (2001) Archeologies of places and Landscapes. En: Hodder, I. (Ed.) Archaeological Theory Today. Londres: Blackwell, pp. 165-186.

» TOMASI, Jorge (2013) Espacialidades pastoriles en las tierras altoandinas: Asentamientos y movilidades en Susques, puna de Atacama (Jujuy, Argentina), Revista de geografía Norte Grande (55), pp. 67-87.

» TOMOEDA, Hiroyasu (1988) 'La llama es mi chacra'. El mundo metafórico del pastor andino. En: Flores, J. (Ed.), Llamichos y Paqocheros. Pastores de Llamas y Alpacas. Cuzco: Centro de Estudios Andinos, pp. 225-235.

» TORRES-ROUFF, Cristina, PIMENTEL, Gonzalo y UGARTE, Mariana (2012) ¿Quiénes viajaban?: Investigando la muerte de viajeros prehispánicos en el Desierto de Atacama (ca. 800 AC - 1536 DC). Estudios Atacameños, (43), pp. 167-186.

» TROMBOLD, Charles (1991) An Introduction to the study of ancient New World road networks. En: Trombold, C. (Ed.), Ancient road networks and settlement hierarchies in the New World. Cambridge University Press, pp. 3-9.

» URRUTIA, Francisca (2011) Participación social en la quebrada de Camiña: entre los avatares de la tradición y la dinámica municipal. Memoria de Título en Antropología Social. Universidad de Chile.

» URZÚA, Luis (1957) Arica, puerta nueva. Historia y folklore. Santiago: Editorial Andrés Bello.

»VALENZUELA, Daniela, SANTORO, Calogero y BRIONES, Luis (2011) Arte rupestre, tráfico e interacción social: cuatro modalidades en el ámbito exorreico de los Valles Occidentales, norte de Chile (períodos Intermedio Tardío y Tardío, ca. 1000-1535 d.C.). En: Núñez, L. y Nielsen, A. (eds.) En ruta. Arqueología, historia y etnografía del tráfico sur Andino. Córdoba: Editorial Brujas, pp. 199-245.

»ZORI, Coleen, BRANT, Erika y URIBE, Mauricio (2017) Empires as social networks: roads, connectedness, and the Inka incorporation of northern Chile. Ñawpa Pacha. Jornal of Andean archaeology, 37(1).

\section{Pablo Méndez-Quirós Aranda / mendez.quiros@gmail.com}

Arqueólogo (Universidad de Chile), Master y Doctor (c) en Arqueología Prehistórica (Universidad Autónoma de Barcelona). Centra su investigación en las sociedades tardías que habitaron el Desierto de Atacama, desde una perspectiva de arqueología del territorio con énfasis en la relación entre asentamientos. Actualmente desarrolla su tesis doctoral sobre la organización social y productiva precolonial en el valle de Lluta. 


\section{Magdalena García Barriga / manegarciab@yahoo.com}

Arqueóloga (Universidad de Chile), Magister y Doctora (c) en Antropología (Universidad Católica del Norte-Universidad de Tarapacá). Socia fundadora y miembro del directorio del Colegio de Arqueólogos de Chile. Se desempeña como especialista en arqueobotánica y en arqueología precolonial de los periodos tardíos (siglos X-XV) en el Norte Grande de Chile. Actualmente, desarrolla un trabajo transdisciplinario con comunidades indígenas trabajando temas de espacio, territorio y asentamiento en la región aymara chilena. 